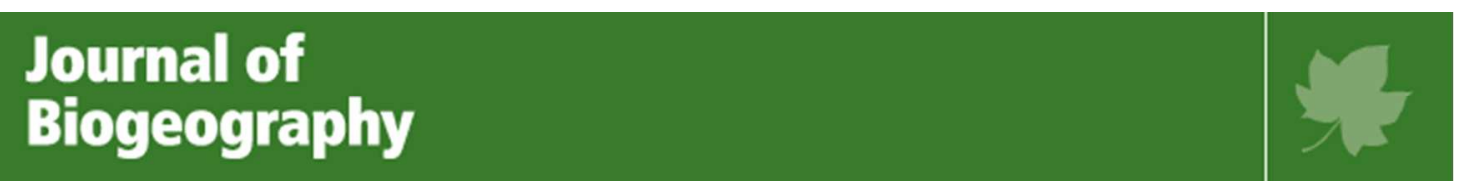

\title{
Community assembly and diversification in a species-rich radiation of island weevils (Coleoptera: Cratopini)
}

\begin{tabular}{|r|l|}
\hline Journal: & Journal of Biogeography \\
\hline Manuscript ID & JBI-16-0520.R2 \\
\hline Manuscript Type: & Research Paper \\
\hline Date Submitted by the Author: & 01-Feb-2018 \\
\hline Complete List of Authors: & $\begin{array}{l}\text { Kitson, James; Newcastle University, School of Biology } \\
\text { Warren, Ben; Museum National d'Histoire Naturelle, Institut de } \\
\text { Systématique, Evolution, Biodiversité } \\
\text { Thébaud, Christophe; Laboratoire Evolution et Diversité Biologique (UMR } \\
\text { 5174), Université Paul Sabatier and CNRS } \\
\text { Strasberg, Dominique; Universite de la Reunion, Faculté des Sciences et } \\
\text { Technologies } \\
\text { Emerson, Brent; Instituto de Productos Naturales y Agrobiologia, CSIC; } \\
\text { University of East Anglia, School of Biological Sciences }\end{array}$ \\
\hline Key Words: & $\begin{array}{l}\text { Colonisation, speciation, extinction, island, invertebrate, diversification, } \\
\text { Mascarene }\end{array}$ \\
\hline \multicolumn{2}{|c}{} \\
\hline
\end{tabular}


Editor: Sanmartín, Isabel

Comments to the Author:

The authors have made a great job in addressing the reviewers' comments from the first round, especially in relation to incorporating inference uncertainty. Yet, this study is so ambitious in scale and scope that some aspects in the methodological approach remain unsatisfactory, in particular the tackling of potential gene tree/species tree incongruence, and the definition of OTUs. Though I agree with the reviewers that further refined analyses are desirable (e.g., Yang \& Rannala's BPP multispecies coalescent model does not require a-priori definition of OTUs and their hierarchical Bayesian approach implies that several sequences per species are not a requisite), my impression is that the scale of this study is so large (+6000 sequences) that these will not have a huge impact on their main conclusions. I therefore suggest the authors to follow the reviewers' suggestions as far as possible and to justify in the text the consequences of their data violating the assumptions of their choice of analyses. I am looking forward to seeing a revised, publishable version of this very important contribution to island biogeography.

Further comments: Together with Richard Ree, I have now a manuscript tentatively accepted in JBI where we demonstrate that biogeographic model selection in BioGeoBEARS is statistically invalid and criticize the $\mathrm{DEC}+\mathrm{J}$ model as a poor model of founder-speciation. $\mathrm{DEC}+\mathrm{J}$ can lead to degenerate probabilistic solutions in which the data is explained entirely by the cladogenetic events and branch length (time) becomes irrelevant. Though certainly the authors could not know this, I would appreciate if they mention this caveat somewhat in Material and Methods. Since the authors are here dealing with island clades and short branch lengths, the use of the DEC+J $(+X)$ model might be not as misleading as when dealing with continental clades subtended by long branches.

"Conceptual and statistical problems with the DEC+J model of founder-event speciation and its comparison with DEC via model selection". Richard H. Ree \& Isabel Sanmartin. Journal of Biogeography.

Dr. Isabel Sanmartín

Dear Dr Sanmartín,

Thank you for the opportunity to resubmit our paper for consideration. Please find below our point by point response to the reviewers. We have attempted the *BEAST analysis suggested by reviewer one but had issues with effective sample sizes even when running the analysis with up to 1 billion generations. We have discussed the implications of gene incongruence in the manuscript as suggested. We have also included your caveat regarding BioGeoBEARS model testing and the $\mathrm{DEC}+\mathrm{J}$ model. This has not been included in the methods but rather in the results directly after the model selection section, as this flows better within the manuscript. We have endeavoured to keep the additional caveats and references requested as short as possible but despite spending much time on reducing the length of this round of changes, it has not been possible to remain below the word limit and we are now 121 words over. We hope that this can be accommodated.

Thank you for your time.

Yours sincerely,

James Kitson (on behalf of the authors) 


\section{REVIEWER COMMENTS TO AUTHOR}

Referee: 1

Comments to the Author

The manuscript has been greatly improved by following many of the reviewers' and the Editor's suggestions. In particular, phylogenetic uncertainty is now accounted for in biogeographic analyses, and a wider range of biogeographic models is explored by using BioGeoBEARS. In my opinion, the paper is essentially acceptable for publication in Journal of Biogeography. Still, there a few points that I think the authors should reconsider when preparing a final version:

- The authors seem very reluctant to use coalescent-based methods (such as *BEAST) in their phylogenetic analysis, despite the fact that the quality of their data would, in principle, permit it. It is true that the authors don't have multiple individuals per OTU sequenced for all four loci, and that is problematic for the estimation of effective populations sizes conducted by *BEAST. However, the authors do have multiple sequences per OTU for one of the loci (COII), and that could be enough to run a reasonably reliable *BEAST analysis (in combination with the single-individual datasets obtained for the other loci, and after excluding the species potentially affected by introgression). I am not saying the authors should redo the whole biogeographic study using a *BEAST phylogeny, but I encourage them to run a ${ }^{*} B E A S T$ analysis to check that topology and divergence times are similar to those of the concatenation-based analysis they have conducted. Given that incongruence between loci seems to be generally low (apart from the case interpreted as resulting from introgression), I expect the results from concatenation and coalescent analyses to be very similar, so major results of the paper shouldn't be affected.

$>$ W We have tried the *BEAST analysis as suggested. Even after 1 billion generations, we still experienced very poor ESS scores $(<50)$ for some parameters. The topology and ages of the tree were comparable but we have not presented this data due to the issues with convergence.

- The authors argue that their "OTU definitions are not specifically meant to represent 'true' species". However, their hypotheses and predictions explicitly deal with speciation, and therefore, a species phylogeny (where OTUs effectively represent 'true' species, at least to a large extent) is required to test them. The potential limitations of this approach should be made clear. >>We acknowledge this limitation but in truth our molecularly defined OTUs confirm several taxonomic synonyms that have been suggested (but not formally described) by previous authors based on sets of species that appear to be forms of each other with varying levels of similarity. For example, the $C$. humeralis group species are distinguished almost entirely by the extent and patterning of the scales coating their elytra. We have addressed this by adding the following sentence to the discussion:

"Our inferences regarding the origins of species diversity are dependent on our OTUs being equivalent to species. Comparison of our OTUs with the most recent taxonomic treatise (e.g. Williams and Cox 2003) support this inference, with recently-defined species corresponding with our OTUs."

Related to this, I am still not convinced by the use of neighbour joining for the analysis of COII sequences to delimit OTUs. I don't see a reason for not using a more reliable method like maximum likelihood.

>> As suggested we have used Maximum Likelihood implemented in RAxML version 7.7.1 through RAxML BlackBox to generate a revised tree. There are no changes to the OTUs defined. We have updated the supplementary figures and relevant text.

- I still think a selection of taxonomic references used for identification should be included in the main text ("Beetle sampling" section of methods). Please note that references in supplementary 
materials are essentially invisible to bibliographic databases (see Rafferty et al., 2015), and this can be particularly detrimental for taxonomists.

>> We agree that this is not ideal (indeed some of the authors of this manuscript suffer the same problem in the citation of their articles). Although would like to cite everything in the main text, we are conscious of the need to endeavour to keep to the word limits for JBI. We have included one or two of the bigger references, which themselves cite the others.

- I am not sure a single nuclear clock is appropriate for the divergence time estimation, given that a broad range of evolutionary rates are expected across the nuclear genome. Has this assumption been tested in any way?

>> This is an approach recommended in several tutorials from the BEAST developers. However, we have tried to run analyses with multiple nuclear clock models. These typically show very poor ESS scores even for long runs. We interpret this as over-parameterisation for the data we have, perhaps due to missing data within some of the nuclear partitions.

A minor point: in Table 1, if I am not mistaken, $\triangle A I C c$ values should be positive, as they represent the difference in AICc between a particular model and the best-fitting model (which has the lowest value). >> The reviewer is correct here. We have updated the table to the correct, positive values.

\section{References}

Rafferty AR, Wong B, Chapple DG. 2015. An increasing citation black hole in ecology and evolution. Ecology and Evolution 5(1): 196-199.

>> An interesting paper and we agree. We have dealt with this above by citing the most important works. 
Referee: 2

Comments to the Author

This is a very impressive study in scope. The authors assembled an enormous dataset of over 6000 weevil specimens to reconstruct the biogeographical history of the tribe Cratopini in the islands of the SW Indian Ocean. Their focus is on the diversity on Mauritius and Reunion, as the authors are using these two islands as a mean to compare how a radiating lineage diversify and multiply on islands of different ages. Mauritius and Reunion are similar in area and isolation, but differ in age (and in elevation). The authors capitalize on the difference in age to test hypotheses related to the theory of island biogeography originally proposed by MacArthur \& Wilson, and the role of colonization and insitu speciation in the formation of diversity. The paper is very well written, the analyses are sound and the conclusions are reasonable given the results. As described below, I only have a few comments/suggestions for the authors to hopefully even further improve the quality of this submission.

(1) In the intro the authors state that the reason why there might be a time lag before in situ speciation starts contributing to island diversity is because speciation takes time - I would be more careful here. We now have many examples of very rapid speciation and another potential explanation for the time lag is the number of "seed" lineages available that can contribute to diversity - the pool of potential colonizer doesn't change much over the young age of an island, but the number of species that can potentially split and give rise to new species in situ increases steadily as species accumulate on the island. There might be a lag in in situ speciation simply because the number of potential "seed" to speciate is very low compared to the pool of species that can reach the island via colonization. > We agree with this important point and it is somewhat encompassed by our statement that "speciation takes time" but for clarity we have now included this reasoning in our first paragraph. It should now be clear that it both takes time for newly arrived lineages to diverge from their source populations and that low initial diversity of arrivals will contribute to reduced speciation potential compared to a fully realised community.

(2) I am not sure I am fully following prediction 2. If I follow the earlier logic of the time lag of in situ speciation, one would expect colonist species to be old, and species resulting from in situ speciation to be relatively younger. The proportion of colonists vs. in situ species should sift over time towards the latter (prediction 1). So on an old island, there should be more species resulting from in-situ speciation relative to colonists (prediction 3). I don't understand why the authors predict species resulting from in situ speciation are likely to be older than colonization events - don't we need a colonization first before we get any speciation within island? Doesn't the rationale above just say the reverse, that the species accumulating early will be doing so via colonization and speciation in situ will kick in later resulting in younger in-situ species compared to colonizer species?

>> In this prediction, we explicitly state that we are not considering the oldest colonisation of the older island. Instead we are examining the relative contribution to the Mauritian community of in situ speciation vs back colonisation from Reunion i.e. is it likely that new colonists are able to establish on Mauritius or are ecological niches filled by in situ speciation? This is linked to your point above, as there are many more 'seed' lineages in an established older community, it is more likely that one of these will lead to the 'successful' lineage that we sampled in the field. The corollary of that is that the constant ecological pressure of established communities would lead to extinction/suppression of new arrivals from Reunion making the sampled back colonisations appear younger overall.

(3) a few places throughout the text (in intro pages 4 and 6, two separate places in discussion pages 20 and 21) the authors interpret their results in light of the balance between formation of species (either in situ or via colonization) and extinction. The authors have zero result enlightening the process of extinction in this group of species and I don't think they can say anything about the rate of extinction in different groups of weevils (whether it is their mode of origin or the flightlessness) given their analyses. I think they should stay away from over interpreting their results in that sense, or if they 
do want to speculate, they should make it clear that their speculation is based on no evidence as related to extinction.

>> Overall we consider that we have been quite careful to avoid suggesting that extinction is the absolute cause of new niches or that it is definitely involved in limiting the diversity of flightless lineages. However, we have removed explicit references to extinction in our predictions and have made clear that we are speculating regarding per-lineage extinction risk for flightless lineages in the discussion. We hope that this removes any ambiguity about whether or not we are testing predictions regarding extinction rates.

(4) The authors should consider addressing briefly in the intro what is the selection agent for the evolution of the loss of flight in arthropods to frame the analysis they are presenting. For example, it is thought that arthropods might lose flight ability at higher elevation. Mauritius is markedly lower than Reunion, could that have played a role in the loss of flight in some species? It is difficult to fully grasp the implication of their analyses on that particular question until they mention a few proposed hypotheses in the discussion. I understand that this paper is not about the transition between flighted and flightless species, but since they are testing for convergence of that trait, it seems to make sense to at least introduce the different potential adaptive values that have been proposed in the literature (and flightlessness is not evolving more often on islands than on continents - see Roff, D.A., 1990. The evolution of flightlessness in insects. Ecological Monographs, 60(4), pp.389-421: "...The incidence of flightlessness increases with altitude and latitude but, contrary to "conventional" wisdom, it is not exceptionally high on oceanic islands compared to mainland areas"-, so putting this in a broader context seems important here).

>> We have followed the reviewer's suggestions and added a few general hypotheses for flight loss in insular insect groups to the introduction. Flightless Cratopine weevils occur in most habitats and at most elevations in the Mascarenes so attributing any of the main flight loss hypotheses already suggested in the literature to this group is not really possible (at least not with the data we have to hand). For this reason we have refrained from making any strong hypotheses for this group specifically.

(5) I think the authors should be more upfront about their 2-step approach of OTU delimitation using COII and then phylogenetic reconstruction of gene and species trees. In a way it is odd to use COII first to establish the units of diversity to be studied, and then use a more complete dataset including nuclear genes to develop a hypothesis of how the lineage evolved (as opposed to use all individuals to do the latter). I understand that given the breadth of sampling, it would be an enormous task to generate the nuclear data for all the $6000+$ individuals for which COll was sequenced. But the method employed here might overlook some important incongruence that is relevant to the biogeographical history and the evolution of flight loss in these weevils. For example, it is unclear whether the signature of variation in island occupancy and flightlessness is not blurred by collapsing groups down to "the minimal monophyletic group containing all samples belonging to one or more taxonomic species". I don't have a better approach to propose, but I think the authors should address the shortcoming of their approach and be clear from the start that this is a choice they made constrained by logistics of sequencing - not a conceptual one (at least that is how I read it).

>> In order to make sure that no biogeographic signal is lost (at least at the inter-island level), we have included, where relevant, a representative of each OTU from each island it occurs on. This is also coincidentally true for flightless species vs flight capable ones. However, we acknowledge that this is indeed a question of logistics and that this should be much clearer in the manuscript so we have amended this section of the methods to explicitly state that is was beyond the scope of this project to sequence all individuals from all localities for multiple loci.

Minor comments:

- page 5 line 35: Not sure that the 10 species of Galapaganus can be considered a "large radiation" 
>> We agree that this is not really a large radiation so have now edited this comment to remove any reference to Galapaganus.

- page 5, line 48: the mathematical/graphical model of theory of island biogeography does not include speciation, but M\&W devoted a section of their book on speciation as a potential source of diversity on islands, so it is not like this is an idea that was only recently brought up.

>> We agree and have amended the manuscript to reference (MacArthur and Wilson 1967) in this statement.

- page 8 line 17, there's a period missing after (Swofford, 2003)

>> Done.

- page 14 lines 12-14: what do the authors mean by "well supported"? did they use some cutoff value for nodal support?

>> For this statement, we have used a cut off value of 0.95 to define well supported. We have amended the text to reflect this.

- page 16 , line 28 , there is an extra "are" in that sentence.

$>>$ Fixed.

- page 16, line 37: the final colonization, do the authors mean the earliest colonization? or first colonization? dating at $8.2 \mathrm{Mya}$, I can't imagine that this is the final (i.e., last colonization)

$>$ We are simply referring to the final colonisation to be discussed. We accept that final in this situation is the incorrect term and is confusing to the reader. We have reworded this to remove ambiguity:

Original:

The remaining two colonisations of Reunion are are followed by back colonisations to Mauritius from Reunion. The first of these occurred approximately 6.4 Mya (95\% HPD 4.1 - 8.8 Mya), giving rise to $C$. septemvittatus and $C$. exquisitus, followed by a recolonisation of Mauritius giving rise to $C$. melanocephalus no more than 3.2 Mya (95\% HPD 1.9 - 4.6 Mya). The final colonisation of Reunion is estimated have occurred approximately 8.2 Mya (95\% HPD 6.3 - 10.3 Mya) giving rise to C. bernei and S. dombayae, with a back colonisation to Mauritius no more than 1.5 Mya (95\% HPD $0.8-2.2$ Mya) giving rise to $S$. subtruncatus.

New version:

The remaining two colonisations of Reunion were followed by back colonisations to Mauritius from Reunion. One occurred approximately 6.4 Mya (95\% HPD 4.1 - 8.8 Mya), giving rise to $C$. septemvittatus and C. exquisitus, followed by a recolonisation of Mauritius giving rise to $C$. melanocephalus no more than 3.2 Mya (95\% HPD 1.9 - 4.6 Mya), while the other is estimated have occurred approximately 8.2 Mya (95\% HPD 6.3 - 10.3 Mya) giving rise to C. bernei and S. dombayae, with a back colonisation to Mauritius no more than 1.5 Mya (95\% HPD $0.8-2.2$ Mya) giving rise to $S$. subtruncatus.

- page 17, lines 25-30. The so called here second colonization seems to also be discordant with the age of Reunion since it should have been the source for that colonization between 7.2 Mya (5.6 - 9.2 Mya) and 8.1 Mya (6.3-10.3 Mya).

>> Thank you for spotting this. You are correct, this is an oversight on our part, given how remote Rodrigues is from Reunion, we would suggest that there are missing intermediate taxa that remain unsampled leading the biogeographic analysis to conclude erroneously that Reunion is the direct source of this colonisation. We have made similar conclusions earlier in the manuscript and amended this section to state: "Given the remoteness of Rodrigues from Reunion, it seems likely that unsampled or extinct species on other islands, especially Mauritius, would be the most probable cause for this discrepancy." 
- page 19, lines 14 and 28, I think it is spelled McDougall, not McDougal >> Corrected.

- Fig 1 looks nice.

>> Thank you!

- Fig 2: The colors are confusing. The clades could be put in boxes with a line but no shading to avoid the confusion of using colors for 2 purposes. I would avoid using dashed branches to illustrate a trait, it is so often used for indicating extinct lineages that this is almost a convention. Why not indicate the flightlessness using a symbol next to the name of the species? You also would avoid implying that the flightlessness evolved at the node connecting the branch to its sister taxon.

$>$ We have made the suggested changes to the figure and figure legend.

- The photos of the weevils are amazing!

>> Thank you, there are some really spectacular species in this radiation. 


\section{Article type: Original Article Community assembly and diversification in a species-rich radiation of island weevils (Coleoptera: Cratopini)}

Running title: Community assembly in Mascarene weevils.

James J. N. Kitson¹, Ben H. Warren², Christophe Thébaud³, Dominique Strasberg4 and Brent C. Emerson ${ }^{5,6}$

${ }^{1}$ School of Natural and Environmental Sciences, Newcastle University, Newcastle upon Tyne, NE1 7RU, United Kingdom.

2 Institut de Systématique, Evolution, Biodiversité, UMR 7205 CNRS MNHN UPMC EPHE, Muséum National d'Histoire Naturelle, Sorbonne Universités, CP 51, 57 Rue Cuvier, 75231 PARIS Cedex 05, France.

${ }^{3}$ Laboratoire Evolution \& Diversité Biologique, UMR 5174 CNRS-Université Paul Sabatier-ENFAIRD, 31062 Toulouse Cedex 9, France.

${ }_{4}^{4}$ UMR PVBMT, Université de La Réunion - Faculté des Sciences et Technologies, CS 92003, 97744 Saint-Denis, La Réunion, France.

${ }^{5}$ Island Ecology and Evolution Research Group, IPNA-CSIC , C/Astrofísico Francisco Sánchez 3, 38206 La Laguna, Santa Cruz de Tenerife, Spain.

${ }^{6}$ School of Biological Sciences, University of East Anglia, Norwich Research Park, Norwich NR4 7TJ, United Kingdom

Correspondence author: James Kitson (James.Kitson@newcastle.ac.uk)

\section{ACKNOWLEDGEMENTS}

We thank Juliane Casquet and Emilie Lesseguince for field assistance and the Mauritian Wildlife Foundation, Vincent Florens, Claudia Baider and Owen Griffiths for logistical assistance. We thank the following people for additional specimens: Antoine Franck, Sylvain Hugel, Jacques Poussereau, Owen Griffiths, Vincent Florens and Claudia Baider, Karl Phillips; Dave Wright; Justin Gerlach; N. Borowiec; Janske van de Crommenacker . We would additionally like to thank Jacques Poussereau for access to his unpublished keys to the Cratopine weevils of Reunion. We are grateful to Conrad Gillett (University of East Anglia) for providing us with the primers ArgK_F1_semidg and ArgK_R2_fulldg. Permits were awarded by the Mauritius National Parks and Conservation Service, the Seychelles Bureau of Standards and the Parc National de La Réunion. Fieldwork and laboratory work were supported by funding from the ANR, France (ANR-2006BDIV002)), and a NERC-funded PhD studentship to JJNK. Molecular analysis training for JJNK was supported by the Company of Biologists and the John and Pamela Salter Charitable Trust. The molecular analyses presented in this study were carried out on the High Performance Computing Cluster supported by the Research Computing Service at the University of East Anglia.

Abstract word count: 300

Total word count: 7121 


\begin{abstract}
Aim Weevils from the tribe Cratopini are found on many of the islands of the Southwest Indian Ocean, with a particularly high species richness in the Mascarenes. We construct a molecular phylogeny to test predictions regarding island age and the relative contributions of colonisation vs. in situ speciation for community assembly and species turnover on Mauritius (approximately $9 \mathrm{Ma}$ ) and Reunion (approximately $5 \mathrm{Ma}$ ), the two main islands of the Mascarenes. We additionally investigate the evolutionary dynamics of flight loss in the tribe, since the loss of flight in island lineages can influence patterns of diversification.

Location Mascarene Islands; Southwest Indian Ocean.

Methods Up to five individuals of each taxonomically described species sampled within each sampling site were sequenced for the mitochondrial gene Cytochrome Oxidase II to delimit operational taxonomic units (OTUs). OTUs were further sequenced for the nuclear genes Arginine Kinase, Histone 3, and ribosomal 28s, to reconstruct the phylogenetic history of the group.

Results Our results support the hypothesis that present-day species richness on the older island of Mauritius is largely the result of in situ speciation, with few colonisation events, of which all but the most basal are recent. In contrast, Reunion presents a more uniform temporal spectrum of colonisation times. Flight loss has evolved convergently at least five times, and speciation events associated with flight loss are significantly younger than speciation events that have not resulted in flight loss.

Main conclusions Patterns of community assembly on the islands of Mauritius and Reunion fit a model where the addition of new species and species turnover is increasingly dominated by in situ speciation as an island community matures. Repeated flight loss indicates selection for flightlessness, with the young age of flightless lineages suggesting higher extinction rates over longer evolutionary time scales and little influence on present-day species richness.
\end{abstract}

\title{
Key words
}

Colonisation, speciation, extinction, island, invertebrate, diversification, Mascarene 


\section{INTRODUCTION}

Island species assemblages result from the accumulation of species through time by colonisation and establishment from outside areas, anagenetic change, in situ speciation and extinction. The relative probabilities of these processes are predicted to be functionally related to each other (e.g. MacArthur \& Wilson, 1963, 1967; Emerson \& Kolm, 2005; Emerson \& Oromí, 2005; Emerson \& Gillespie, 2008). A time lag before in situ speciation begins to contribute to island community assembly can be expected, given that: (i) speciation takes time; (ii) speciation between island and mainland source populations may be needed before in situ speciation can occur, and; (iii) an initially low number of established lineages means there are fewer lineages across which speciation can occur. It has been further hypothesised that community assembly on young islands should initially be dominated by colonisation, but that in situ speciation should later make an important contribution, giving rise to a dynamic equilibrium of species turnover involving colonisation, extinction and speciation (e.g. Emerson \& Oromí, 2005; Emerson \& Gillespie, 2008). Under this model one would expect that for islands belonging to the same regional species pool, and with a comparable size and species richness, but of different ages, species origin by in situ speciation would be more predominant on older islands, assuming that younger islands had not reached a turnover equilibrium among colonisation, speciation and extinction.

The Indian Ocean islands of Mauritius and Reunion offer a near-ideal opportunity to examine the temporal dynamics of community assembly, as both islands are of a similar size and isolation from source areas of colonisation, but are of markedly different ages (Thébaud et al., 2009; Casquet et al., 2015). The subaerial age of Mauritius is estimated to be approximately 8.9 Ma (million years) (Moore et al., 2011), while the age of Reunion is estimated to be up to $5 \mathrm{Ma}$ (Bonneville et al., 1988). The closest longterm source area for both islands is Madagascar, from which both can be considered to be similarly isolated, being $870 \mathrm{~km}$ and $665 \mathrm{~km}$ away, respectively. Connectivity of both islands with the Seychelles and India has been promoted by the appearance of stepping stone islands along the Mascarene plateau during cycles of sea-level low stands (Warren et al., 2010).

One of the most species rich invertebrate groups distributed across the islands of the Southwest Indian Ocean is the weevil tribe Cratopini, which is represented by five of the nine recognised genera (Alonso-Zarazaga \& Lyal, 1999). Species richness is concentrated on the islands of Mauritius and Reunion, with 75 of the approximately 107 described species of Cratopus (abbreviated to C.), 12 of the 14 described species of Cratopopsis (abbreviated to $\mathrm{Cr}$.) and both described species of Scaevinus. Cratopine weevils of the Southwest Indian Ocean Islands are unusual in that a large proportion of species are flighted, contrasting with other known large radiations of oceanic island weevils where all species are flightless (e.g. the genus Laparocerus in Macaronesia and Rhyncogonus in Polynesia). While Cratopus species are capable of flight, with the exception of one flightless species (C. triangularis) and one flight polymorphic species, C. murinus [Kitson et al. (2013)], all Cratopopsis and Scaevinus species are exclusively flightless.

The equilibrium model of island biogeography (MacArthur \& Wilson, 1963, 1967) emphasizes island biotas as being typified by rapid turnover through ongoing colonisation and extinction (Heaney 2007). While the equilibrium model does not explicitly include speciation, it is expected that species turnover will be increasingly dominated by in situ speciation as an island community matures (addressed by 
MacArthur \& Wilson, 1963; e.g. Emerson \& Oromí, 2005; Emerson \& Gillespie, 2008). It thus follows that colonisation would be expected to contribute more to species richness on the younger island of Reunion, because it is in a younger stage of the community assembly/species turnover spectrum (sensu Whittaker et al., 2008), and less to the more mature island of Mauritius, because it is at a later stage. Here we reconstruct phylogenetic relationships among cratopine weevils of the Mascarene Islands to infer the biogeographic history of the group, and to test the hypothesis that in situ speciation contributes proportionally more to species richness on mature islands (Mauritius) than on younger islands (Reunion). We explore this dynamic by distinguishing between divergence events that have added species to an island by colonisation from those that have added species through in situ speciation, and by testing the following three predictions: (i) the probability of establishment and persistence of a colonising species decreases as an island matures, (ii) excluding the earliest colonisation event, in situ speciation events on a mature island are more likely to be older than colonisation events, reflecting a dynamic dominated more by species turnover within the local species pool rather than colonisation of empty niche space by the regional species pool; and (iii) in situ speciation events on young islands are more likely to be of comparable age or even younger than colonisation events, reflecting a dynamic dominated more by colonisation of unoccupied ecological niches by the regional species pool, rather than species turnover within the local species pool.

An important part of community assembly is in situ evolution following colonisation, as colonist lineages adapt to their new niche. A recurring feature of this process in many insular insect and vertebrate groups is the loss of flight (Wright et al., 2016) with multiple hypotheses for this trend being proposed such as; reduced temperature at high altitude (Medeiros \& Gillespie, 2011), strong winds displacing individuals from restricted environments (Sattler, 1991) and increased fecundity due to rebalancing an organism's energy budget (Roff, 1990). Loss of flight is particularly relevant in the context of community assembly within islands or groups of islands, as it can accelerate allopatric speciation and promote diversification, as shown in carrion beetles (Ikeda et al., 2012). Given that many weevil genera present on archipelagos are flightless (see Williams, 2000; Samuelson, 2003; Machado et al., 2008 for examples), the occurrence of just two flightless species within the otherwise flight capable genus Cratopus is surprising. However, the number of flight loss events within the Cratopini of the Southwest Indian Ocean Islands may be underestimated by taxonomy. The monophyly of the genus Cratopopsis in particular is defined by morphological characteristics that could be the consequence of convergent evolution through the repeated evolution of flight loss (partially fused elytra and reduced prothoracic anatomy). Thus it is possible that cratopine taxonomy is a poor predictor of the evolutionary history within the tribe. We used our phylogenetic data to re-examine the evolutionary dynamics of flight loss in Mauritius and Reunion Cratopini to assess the frequency and timing of speciation events associated with flight loss, and their potential influence on patterns of community assembly.

\section{METHODS}

\section{Beetle sampling}

Specimens were collected from the islands of the Southwest Indian Ocean by foliage beating during wet seasons between June 2007 and December 2011. Samples were 
placed directly in 99\% ethanol and sampling sites were recorded with a handheld GPS unit. Samples were identified to taxonomic species using morphological keys for Cratopus and Cratopopsis provided by Jaques Poussereau (unpublished work) and the original descriptions of most species (Hustache, 1919; Williams \& Cox, 2003 - but see Appendix S1.2 in Supplementary Materials for more references).

\section{Defining operational taxonomic units for the multilocus phylogeny}

While there is a rich taxonomic literature for the three Cratopine genera of the Southwest Indian Ocean (see Appendix S1.2), the validity of several Mascarene species has been questioned (Voisin \& Poussereau, 2009). To address the taxonomic uncertainty within the group, we used a phylogenetic approach to help define operational taxonomic units (OTUs). It was beyond the scope of this project to sequence all samples for multiple loci so we first selected up to five individuals per species per Mascarene sampling locality for genomic DNA extraction, PCR, and sequencing of the mitochondrial locus Cytochrome Oxidase II (COII). All COII sequences locus were aligned using MAFFT v6.814b and model testing was undertaken to determine the best phylogenetic model in jModeltest2 (Darriba et al., 2012). A maximum likelihood tree was generated using the GTRGAMMA model in RAxML 7.7.1 (Stamatakis et al., 2008) using the RAxML BlackBox (https://embnet.vital-it.ch/raxml-bb/index.php). Operational taxonomic units (OTUs) were then defined as the minimal monophyletic group containing all samples belonging to one or more taxonomic species. If an OTU occurred on multiple islands, then a representative from each island was included in the multilocus phylogeny. Single individuals of species from islands outside the Mascarenes were also included in the final set of OTUs. Full details of the procedure for OTU definition (including PCR conditions and sequencing) can be found in Appendix S1.

\section{Molecular protocols for phylogenetic analyses}

To reconstruct phylogenetic relationships among the defined OTUs, individuals were chosen for the amplification and DNA sequencing of three additional loci: Arginine Kinase (ArgK), Histone 3 and the ribosomal gene 28S. Sequences for all primers used can be found in Table S1.6.2 and detailed molecular methods including PCR conditions are available in Appendix S1.6.

All sequences were checked, and in the case of reverse sequencing, consensus sequences generated with Geneious Pro version 5.6. Sequences were aligned using MAFFT v6.814b (Katoh et al., 2002) with the following parameter values: scoring matrix $1 \mathrm{PAM} / \mathrm{k}=2$, Gap open penalty $=1.53$, Offset value $=0.123$, and then checked by eye. The aligned sequences were tested for saturation using the entropy-based index of substitution saturation as implemented in DAMBE v5.2.78 (Xia et al., 2003). This was performed on two data sets, one comprised of the first and second codon positions and the second comprised of the third codon positions, with the exception of $28 \mathrm{~S}$ which was not partitioned.

\section{Phylogenetic analyses}

Trees for OTUs defined from the mtDNA COII analysis were constructed from individual alignments of each locus using MrBayes 3.2 (Huelsenbeck \& Ronquist, 2001). Four MrBayes replicate analyses were performed on each alignment for 20 million generations using eight MCMC chains, discarding 25\% of the samples as burnin. Model testing was undertaken to determine the best model for each locus in jModeltest2 (Darriba et al., 2012). The alignments for COII, ArgK and H3 were assigned the GTR+G 
substitution model and $28 \mathrm{~S}$ was assigned the $\mathrm{HKY}+\mathrm{I}+\mathrm{G}$ model, all parameters permitted under these models were estimated. The outputs of all MrBayes analyses were assessed for stationarity and convergence in Tracer v1.5.0 (Rambaut \& Drummond, 2007) and AWTY (Nylander et al., 2007), and only runs with ESS scores greater than 200 for all parameters were accepted. Consensus trees were plotted and formatted in $R$ ( $R$ Development Core Team, 2017) using the 'ggtree' R package (Yu et al., 2017). Before performing multilocus analyses, congruence between gene trees was assessed by comparing consensus tree for each gene to check for conflicting well supported clades ( $>0.95$ Bayesian posterior probability) present in one partition but not the others as (as in Meseguer et al., 2013). In addition to this, a sensitivity analysis was performed as in Meseguer et al. (2013) to examine the effects of missing data. Four separate concatenated alignments were produced: (1) all-samples; (2) samples with at least two loci; (3) samples with at least three loci; (4) samples which have all four loci. Each concatenated alignment was analysed using the same parameters as above with all substitution model parameters unlinked for each partition.

\section{Divergence time estimation}

Timings of colonisation and divergence events were estimated with BEAST2 v2.4.5 (Bouckaert et al., 2014) using all four loci. Each partition was given the substitution model previously determined by jModeltest 2 and all substitution models were unlinked to allow each partition to have its own parameters. Ten replicate analyses each of 100 million generations were performed. The COII partition was assigned a relaxed lognormal clock model with a mean rate of 0.0154 substitutions/site/Ma with a standard deviation of 0.06, taken from (Cicconardi et al., 2009). A single nuclear clock, estimated relative to the COII clock, was applied to all nuclear partitions. Stationarity and convergence were assessed as with the individual locus MrBayes trees. A maximum clade credibility (MCC) tree was generated from the BEAST2 output by combining tree files in Logcombiner v2.4.5 (Bouckaert et al., 2014) and then generating the MCC tree in TreeAnnotator v2.4.5 (Bouckaert et al., 2014).

\section{Biogeographic analyses}

For all analyses, the Seychelles were treated as a single island as they have formed one connected landmass at least six times due to changing sea levels over the last 500,000 years (Warren et al., 2010). All other islands were treated as independent entities as they are surrounded by deep water and are unlikely to have ever been connected. Ancestral ranges for each node in the multilocus phylogeny were estimated using the BioGeoBEARS package (Matzke, 2013) in R. All of the base models DEC (Ree \& Smith, 2008), DIVALIKE and BAYAREALIKE (maximum likelihood implementations of DIVA Ronquist \& Cannatella, 1997; and BAYAREA - Landis et al., 2013) were used for model testing in conjunction with the founder event (+J - Matzke, 2014) and distance based dispersal (+X -Van Dam \& Matzke, 2016) modifiers giving a total of twelve possible biogeographic models. The best model was chosen using relative model probability with any model with a relative probability less than 0.05 being discounted and $\triangle \mathrm{AICc}$ (corrected Akaike information criteria) values $>2$ being used as a cutoff between the most similar models (Burnham \& Anderson, 2002).

\section{Statistical analysis of node ages}

Statistical tests comparing nodal ages were performed to test if: nodes representing colonisations of Mauritius are younger than nodes representing colonisations of 
Reunion (prediction 1); nodes representing colonisations of Mauritius are younger than nodes representing in situ speciation on Mauritius (prediction 2); nodes representing in situ speciation events on Reunion are younger than nodes representing colonisation events of Reunion (prediction 3). Nodes leading to flight loss were also tested to evaluate if they are significantly younger than other nodes, as might be expected if there is high evolutionary turnover of flightless lineages. To account for uncertainty in the estimated phylogenetic history and node ages, the above analysis was replicated across 1000 random trees drawn from the post burnin BEAST2 .trees files. For each node in each randomly selected tree, the most probable biogeographic range for that node and the ancestor of that node were extracted from the BioGeoBEARS output along with the median age of each node. These were then used to identify the node types listed above and calculate the maximum possible age for each colonisation or in situ speciation event. The mean age of each node was then used in a series of t-tests that were paired to account for overall variation in tree age. R scripts for subsampling of BEAST2 trees and performing the BioGeoBEARS analysis are available as part of our supplementary GitHub repository.

\section{RESULTS}

\section{Beetle sampling}

A total of 5565 beetles were collected across 19 islands, representing 77 described species, accounting for approximately $70 \%$ of the recognised species richness. A complete list of species and islands is provided in Table S2.3 in Appendix S2.

\section{Operational taxonomic units}

Subsampling five individuals, where possible, of each taxonomic species sampled within each Mascarene sampling site resulted in a dataset of 915 individuals for the definition of OTUs. A full list of Mascarene sites and GPS coordinates can be found in Table S1.2.1 in Appendix S1. A total of 32 OTUs were identified across the Mascarenes (See Figures S1.5.1 and S1.5.2 in Appendix S1 for OTUs and the taxonomic species they contain). There are an additional 19 species from non-Mascarene islands, four OTUs that are shared across islands, two species that did not amplify for COII and one outgroup (Polyclaeis equestris) giving 58 OTUs in the final dataset.

\section{DNA sequencing for the OTU phylogeny}

A full summary of sequencing success for each locus can be found in Table S2.4 in Appendix S2 while Table S2.5 in Appendix S2 contains the corrected and uncorrected genetic distances among individuals for each locus. The sequencing success for each OTU partitioned by locus is provided in Table S2.6 in Appendix S2. All sequences are available on GenBank (accession numbers will be provided upon acceptance). The results of Xia's test for saturation for each locus divided into first and second codon position vs. third codon position (except $28 \mathrm{~S}$ which was not partitioned) is provided in Table S2.7 in Appendix S2. Results indicate that sequences are not saturated with the possible exception of the third codon position for COII which had a test statistic that was not significantly less than the critical value. 


\section{Phylogenetic analyses of individual genes}

Among the four partitions, the COII (Fig S2.3 in Appendix S2) and ArgK (Fig. S2.4 in Appendix S2) trees are better supported, with ArgK providing greater resolution among basal nodes. The Histone 3 (Fig. S2.5 in Appendix S2) and 28S (Fig. S2.6 in Appendix S2) trees are less well supported. Histone 3 contains much missing data $39.0 \%$ of the alignment is missing or ambiguous compared to $6.8 \%$ for COII, no missing data for ArgK and $2.1 \%$ for $28 \mathrm{~S}$ ). The lack of support in the $28 \mathrm{~S}$ tree is consistent with the low number of variable sites $(90.2 \%$ of aligned sites are identical compared to $59.4 \%$ for COII, $65 \%$ for ArgK and $64.3 \%$ for Histone 3). The individual gene trees are in broad agreement with one notable exception. Cratopopsis bistigma from Reunion and the Mauritius Cratopopsis OTU are recovered as sister OTUs with very high support for all nuclear loci. However Cr. bistigma is recovered with very high support as a sister species to $C$. frappieri, also from Reunion, in the COII tree. The sequences for the Mauritius Cratopopsis OTU and Cr. bistigma were confirmed by repeat PCR and resequencing. The incongruent mtDNA relationships among the three OTUs was also evident within the broader mtDNA analysis to define OTUs, indicating that the incongruence between nuclear and mitochondrial loci is not due to error. An explanation of incomplete lineage sorting can be excluded due to both the phylogenetic depth involved and limited opportunity in the context of island colonisation (see Faria et al., 2016), indicating mtDNA introgression from $C$. frappieri to Cr. bistigma. Because of this, the COII partition for Cr. bistigma was excluded from the multilocus phylogenetic alignment. As with individual gene analyses, the trees produced by the sensitivity analysis were in broad agreement. Overall we found no large changes in tree support when including missing data with: $71.2 \%$ of nodes were well supported ( $\geq 0.95$ Bayesian posterior probability) in the all sample analysis (58 OTUs); $70.8 \%$ with a minimum of two loci (54 OTUs); $71.1 \%$ with a minimum of three loci (52 OTUs); and, $74.2 \%$ with a minimum of four loci (37 OTUs). Subsequent analyses were thus performed using the four locus matrix for all 58 0TUs.

\section{Multilocus phylogenetic analysis}

The concatenated multilocus alignment of the 58 OTUs was 2,173 bp long. Overall, the MCC chronogram (Fig. 2. See Fig. S2.7 for HPD intervals on node ages) is generally well supported and can be divided into two main clades. Clade one contains much of the diversity from the Seychelles and the Comoros with some additional species from Rodrigues, Mauritius and Reunion. Clade 2 includes most species from Mauritius and Reunion and all of the species strictly associated with coralline or coastal habitats in the smaller islets of the Indian Ocean and the Seychelles (C. gloriosus, C. adspersus, $C$. viridisparsus and $C$. griseovestitus). Clade two can be further divided into three subclades (Fig. 2, Clades $2 \mathrm{a}, 2 \mathrm{~b}$ and $2 \mathrm{c}$ ). Clades $2 \mathrm{~b}$ and $2 \mathrm{c}$ are well supported but the arrangement of relationships among them and clade $2 \mathrm{a}$ is poorly resolved, largely due to the unresolved position of $C$. nigrogranatus. Cratopus and Cratopopsis are not recovered as reciprocally monophyletic, with Cratopopsis OTUs occurring in both clades and two of the three subclades of clade two. Rodrigues and Reunion each have their own Cratopopsis lineage and a third is represented on both Mauritius and Reunion. Scaevinus is recovered within clade 1 as a sister lineage to $C$. bernei.

\section{Biogeographic and dating analyses}

Model testing in BioGeoBEARS indicated that $\mathrm{DEC}+\mathrm{J}+\mathrm{X}$ is the best fitting model to the MCC chronogram (see Table 1 for model testing results). DIVALIKE+J+X had a 
marginally significant relative model probability but it was discarded as significantly worse than $\mathrm{DEC}+\mathrm{J}+\mathrm{X}$ because the $\triangle \mathrm{AICc}$ value was greater than two between the models. All of the most probable models contain both the $+\mathrm{J}$ and $+\mathrm{X}$ modifiers indicating that both long range dispersal and the distance between islands are important in the biogeographic history of Cratopine weevils. It should be noted however that there is criticism of how BioGeoBEARS implements model selection and that the DEC $+\mathrm{J}$ model may be inappropriate for phylogenies with long branch lengths (Ree \& Sanmartin, 2018- unpublished), although it is unlikely to be consequential here as are dealing with relatively short branches. Figure 2 shows the results of the stratified DEC $+\mathrm{J}+\mathrm{X}$ analysis performed on the BEAST2 MCC chronogram. All general biogeographic discussion refers to this analysis while the statistical analysis of node ages (next section) employs the same biogeographic model but iterates across a random sample of 1000 dated trees from the BEAST2 posterior.

Overall, the biogeographic history estimated on the BEAST2 MCC tree (Fig. 2) suggests that the sampled diversity arose from an ancestor on Mauritius. The DEC+J+X analysis infers nine colonisations from Mauritius to Reunion and three colonisations from Reunion to Mauritius. There are two inferred colonisations to Rodrigues, two to the Seychelles and two to the Comoros. One of the two colonisations to each of the Seychelles and the Comoros involves a group of species that have colonised coastal habitats in Mauritius, Reunion and the Comoros and eventually northwards to the Seychelles.

Of the nine colonisations from Mauritius to Reunion inferred by BioGeoBEARS, four have a median estimated divergence time of two million years or less. Most of these have resulted in taxonomically defined species that are extremely similar (Scaevinus dombayae, Fig.2 clade 1, Cr. bistigma and C. brunnipes, Fig. 2, clade 2b) to their counterparts on Mauritius while the remaining colonisation (the $C$. nigridorsis species group, Fig. 2, clade $2 \mathrm{~b}$ ) is represented by a single OTU containing three taxonomically defined species. A fifth colonisation of Reunion is estimated to have occurred approximately 4.8 Mya (Million years ago) (95\% HPD 3.6 - $6.2 \mathrm{Mya}$ ), giving rise to the remaining Cratopopsis from Reunion (seven taxonomically defined species), C. nanus, $C$. ditissimus and the $C$. humeralis species group (four taxonomically defined species). Two further colonisations of Reunion occurred 4.2 Mya (95\% HPD 2.8 - 5.7 Mya) and 2.6 Mya (95\% HPD 1.7 - 3.7 Mya) respectively with one colonisation resulting in C. frappieri (Fig 2 , clade 2 b) and another resulting in C. murinus (Fig2, clade 2c).

The remaining two colonisations of Reunion were followed by back colonisations to Mauritius from Reunion. One occurred approximately 6.4 Mya (95\% HPD 4.1 - 8.8 Mya), giving rise to $C$. septemvittatus and $C$. exquisitus, followed by a recolonisation of Mauritius giving rise to $C$. melanocephalus no more than 3.2 Mya (95\% HPD 1.9 - 4.6 Mya), while the other is estimated have occurred approximately 8.2 Mya (95\% HPD 6.3 10.3 Mya) giving rise to $C$. bernei and $S$. dombayae, with a back colonisation to Mauritius no more than 1.5 Mya (95\% HPD 0.8 - 2.2 Mya) giving rise to S. subtruncatus. The 95\% HPD interval of this event does not include the maximum estimated age of Reunion, invoking either (i) an older age for Reunion, (ii) an underestimation of molecular rate, or (iii) colonisation associated with a more recent node, but this is masked by unsampled or extinct Mauritian taxa within this clade. The third colonisation from Reunion to Mauritius is inferred to have occurred at least 1.2 Mya (95\% HPD 0.6 - 1.8 Mya) leading to the Mauritian population of C. punctum.

Lineage 2c contains the exclusively coastal species $C$. punctum, C. griseovestitus, $C$. viridisparsus, C. adspersus, C. gloriosus, Cratopus GrandeComore sp. 1 and Cratopus Moheli 
sp. 1. Dating analyses suggest the diversification among these taxa began approximately 2.1 Mya (95\% CI 1.5 - 2.7 Mya), radiating from Reunion to the low lying islands of Juan de Nova, Europa, Grande Glorieuse and Aldabra not less than 1.1 Mya (95\% HPD 0.8 1.5 Mya), followed more recently by a colonisation of Seychelles not less than less than 0.5 Mya (95\% HPD 0.3 - 0.8 Mya).

Rodrigues is inferred to have been colonised twice. A colonisation giving rise to C. virescens and C. viridipunctatus (Fig. 2, clade $2 \mathrm{~b}$ ) is inferred to have its source on Mauritius and to have occurred at least 3.8 Mya (95\% HPD 2.4 - 5.4 Mya). The second colonisation gave rise to $C$. inornatus, $C$. rocki and $C r$. pauliani (Fig. 2, clade 1), with Reunion inferred as the most probable source between 7.2 Mya (95\% HPD 5.6 - 9.2 Mya) and 8.1 Mya (95\% HPD 6.3 - 10.3 Mya). As with the genus Scaevinus, the 95\% HPD interval of this event does not include the maximum estimated age of Reunion. Given the remoteness of Rodrigues from Reunion, it seems likely that unsampled or extinct species on other islands, especially Mauritius, would be the most probable cause for this discrepancy.

The remaining species in clade 1 are recovered in two well supported groups. The first consists of species restricted to the granitic Seychelles while the second exclusively contains species from the Comoros. The granitic Seychelles appear to have been colonised by the ancestor of Cratopus La Digue sp. 1, Cratopus Mahe sp. 1, C. segregatus and C. aurostriatus at least 4.3 Mya (95\% HPD 3.0 - 5.8 Mya) while the Comoros are estimated to have been colonised by the ancestor of $C$. subdenudatus, Cratopus Anjouan sp. 1 and Cratopus Anjouan sp. 2 at least 3.8 Mya (95\% HPD 2.8 - 5.1 Mya).

\section{Statistical analysis of node ages}

Across all 1000 trees, there was a mean of 8.97 colonisations from Mauritius to Reunion and 3.03 colonisations from Reunion to Mauritius (mean difference 5.94 colonisations, $95 \% \mathrm{CI}=5.92$ to $5.95, \mathrm{t}=665.9, \mathrm{df}=999, \mathrm{p}<0.0001$ ). Colonisations of Mauritius from Reunion are inferred to be significantly younger than those of Reunion from Mauritius (mean difference $=-1.07 \mathrm{Ma}, 95 \% \mathrm{CI}=-1.10$ to $-0.1 .04 \mathrm{Ma}, \mathrm{t}=-66.0, \mathrm{df}=999, \mathrm{p}<$ 0.0001). Colonisation events to Mauritius are inferred to be significantly younger than in situ speciation events (mean difference $=-2.19 \mathrm{Ma}, 95 \% \mathrm{CI}=-2.22$ to $-2.16 \mathrm{Ma}, \mathrm{t}=-$ 120.3 , df $=999, \mathrm{p}<0.0001)$. In situ speciation events on Reunion are inferred to be significantly younger than colonisation events (mean difference $=-0.097 \mathrm{Ma}, 95 \% \mathrm{CI}=-$ 0.116 to $-0.078 \mathrm{Ma}, \mathrm{t}=-10.275, \mathrm{df}=999, \mathrm{p}<0.0001$ ). Statistical analyses of node ages indicate that nodes leading to flight loss are significantly younger than other nodes (mean difference $=-1.327 \mathrm{Ma}, 95 \% \mathrm{CI}=-1.344$ to $-1.1 .308 \mathrm{Ma}, \mathrm{t}=-146.7, \mathrm{df}=999, \mathrm{p}<$ 0.0001 ) indicating that flight loss is a relatively recent phenomenon within this group, or alternatively that flightless lineages show high extinction rates.

\section{DISCUSSION}

\section{Biogeography of Southwest Indian Ocean cratopine weevils}

In addition to addressing our hypotheses, the phylogenetic analyses provide an overview of the colonisation dynamics that has given rise to the diversity of cratopine weevils in the islands of the Southwest Indian Ocean. Rodrigues has been colonised twice, as have both the Seychelles and Comoros archipelagos. The more recent colonisation of both the Seychelles and Comoros archipelagos also involves 
colonisations of the islands to the northeast (Aldabra and Grande Glorieuse) and southwest (Juan de Nova and Europa) of the Comoros archipelago with an apparent source on Reunion. The older colonisation of both archipelagos is inferred to be from Rodrigues. Warren et al. (2010) have described how sea level changes in the Indian Ocean over at least the last five million years would have exposed many now submerged islands of the Mascarene plateau. Thus stepping stone islands are likely to have been intermittently present over much of the evolutionary history of the cratopine weevils, potentially providing routes for dispersal between the granitic Seychelles, the Comoros and Rodrigues.

The estimated colonisation times for Rodrigues are significantly older than its presumed age. The 1.5 Ma age for Rodrigues suggested by McDougall et al. (1965) and based on the oldest exposed lavas falls outside the 95\% HPD interval for both colonisation events. Additionally, all three speciation events within Rodrigues are estimated to significantly predate $1.5 \mathrm{Ma}$. It may be that our mutation rate overestimates divergence times within the Cratopini, but it has previously been suggested that Rodrigues is much older than 1.5 Ma (Thébaud et al., 2009; Warren et al., 2013; Strijk et al., 2014), and the estimates of McDougal et al. (1965) do not sample older buried strata, nor take into account those removed by extensive erosion (Montaggioni \& Nativel, 1988).

All nodes inferred as having their most probable location on Mauritius are either younger than or have confidence intervals that include the 8.9 Ma provided by Moore et al. (2011). While the oldest nodes involving Reunion are much older than the 2.0 Ma age for the oldest lavas sampled on Reunion (McDougall, 1971), all but one are consistent with the maximum 5 Ma inferred using methods other than radiometric dating of lavas (Bonneville et al., 1988). While estimates of molecular rate and island age may hold some explanation for this single difference, no speciation events within Reunion exceed its $5 \mathrm{Ma}$ age estimate. An alternative explanation is that colonisation time is overestimated due to unsampled or extinct taxa from Mauritius.

\section{Island age, community assembly and species turnover}

Biogeographic inference of ancestral areas supports the hypothesis that in situ speciation has contributed more to cratopine species richness on the older island of Mauritius than it has on the younger island of Reunion. Our inferences regarding the origins of species diversity are dependent on our OTUs being equivalent to species. Comparison of our OTUs with the most recent taxonomic treatise (e.g. Williams \& Cox, 2003) support this inference, with recently-defined species corresponding with our OTUs. Our first prediction that colonising species to Mauritius should have lower persistence times, compared to those colonising Reunion, is supported by the statistical analysis of node ages. Mauritius is characterised by older in situ speciation events, with younger colonising lineages, supporting prediction two. With regard to Reunion, likelihood inferences suggest that species origin by colonisation has been more predominant in the history of the island, with the contribution of in situ speciation appearing in only a small subset of lineages present on the island, supporting prediction three.

Results are largely consistent with the expectation that the contribution of colonisation to community assembly is more important in the early stages of assembly, with speciation assuming a more dominant role as community assembly gives way to a dynamic of species turnover (Emerson \& Oromí, 2005; Emerson \& Gillespie, 2008), which is expected under the equilibrium model (Heaney, 2007). Over evolutionary time, 
it appears that niche space within an island becomes occupied by colonising species. Newly arriving species are less able to establish and remaining niche space becomes increasingly likely to be colonised by resident species through in situ speciation, as are niches that may become vacant through extinction (Emerson \& Oromí, 2005; Emerson \& Gillespie, 2008).

\section{Polyphyly of Cratopopsis and loss of flight capability}

Our data demonstrate that the genera Cratopus and Cratopopsis are not monophyletic (Fig. 2), with at least three independent instances of the Cratopopsis morphology evolving convergently within Cratopus. Cratopopsis species mainly differ from Cratopus by a lack of wings and a characteristically-shaped reduced thorax that is probably associated with a loss of flight musculature. This pattern is seen more widely in the tribe with at least two further flight loss events (in C. murinus and Scaevinus) and the number of events may be higher, as two flightless Indian Ocean cratopine weevils were not sampled (C. triangularis from Mauritius and Cr. matilei from Anjouan). A number of authors have argued that there are benefits to flightlessness, such as energetic savings and increased reproductive output (Roff, 1990), and selection against dispersal has also been hypothesised for organisms inhabiting limited habitat patches (Harrison, 1980). A tendency toward flightlessness is part of a wider pattern seen in beetles on islands, with examples from many archipelagos [e.g Rhyncogonus of Polynesia (Samuelson, 2003), Laparocerus of Macaronesia (Machado et al., 2008)]. While there has been repeated selection for flightlessness within the Cratopini of the Indian Ocean, our statistical analysis of node ages indicates that flightless lineages are significantly younger than flighted lineages. Rather than flight loss being a recent phenomenon within this group, we speculate that it is more likely to be a recurrent phenomenon, but characterised by a higher per species extinction probability for flightless species than flighted species.

\section{CONCLUSIONS}

Phylogenetic reconstruction and ancestral area inference indicate that the extensive radiation of Cratopine weevils across the islands of the Indian Ocean has occurred within the last 10 million years, with the earliest diversification events inferred to have occurred on the island of Mauritius. Geographic inferences for colonisation and speciation on the species rich islands of Mauritius and Reunion are consistent with predictions from equilibrium theory regarding species turnover, when extended to incorporate speciation. Compared to Mauritius, colonisation is found to have contributed more to species richness on Reunion, consistent with its younger geological age and earlier stage of community assembly. In contrast, much of the species richness on the older island of Mauritius is consistent with a more mature community dynamic where turnover is dominated by in situ speciation of already established lineages. These data offer support for a model where island community assembly is initially dominated by colonisation, but where in the later stages of an island life-cycle, turnover is more likely to involve species replacement by speciation within the island, rather than colonisation from an external source. 


\section{TABLES}

Table 1: Statistical comparison of biogeographic models tested. Relative model probability indicates that $\mathrm{DEC}+\mathrm{J}+\mathrm{X}$ is the best fit model for the data.

\begin{tabular}{|c|c|c|c|c|c|c|c|c|c|}
\hline & LnL & $\begin{array}{c}\text { Number of } \\
\text { parameters }\end{array}$ & $\mathbf{d}$ & $\mathbf{e}$ & $\mathbf{j}$ & $\mathbf{x}$ & $\mathbf{A I C c}$ & $\mathbf{\Delta A I C c}$ & $\begin{array}{c}\text { Relative model } \\
\text { probability }\end{array}$ \\
\hline DEC+J+X & -82.62 & 4 & $1.00 \mathrm{E}-12$ & $1.00 \mathrm{E}-12$ & 0.0061 & -1.72 & 174 & 0 & 1 \\
\hline DIVALIKE+J+X & -85.42 & 4 & $1.00 \mathrm{E}-12$ & 0.78 & 0.0088 & -1.41 & 179.6 & 5.59 & 0.061 \\
\hline BAYAREALIKE+J+X & -88.03 & 4 & 0.0000001 & 1.21 & 0.0061 & -1.77 & 184.8 & 10.81 & 0.0045 \\
\hline DIVALIKE+J & -102.4 & 3 & $1.00 \mathrm{E}-12$ & $1.00 \mathrm{E}-12$ & 0.033 & 0 & 211.3 & 37.26 & $8.10 \mathrm{E}-09$ \\
\hline BAYAREALIKE+J & -106.5 & 3 & 0.0000001 & 0.58 & 0.035 & 0 & 219.5 & 45.5 & $1.30 \mathrm{E}-10$ \\
\hline DEC+J & -109.3 & 3 & $1.00 \mathrm{E}-12$ & 1.72 & 0.034 & 0 & 225.1 & 51.06 & $8.20 \mathrm{E}-12$ \\
\hline DIVALIKE+X & -121.8 & 3 & 0.15 & 0.0000013 & 0 & -1.29 & 250 & 76 & $3.10 \mathrm{E}-17$ \\
\hline DIVALIKE & -137.8 & 2 & 0.63 & $1.00 \mathrm{E}-12$ & 0 & 0 & 279.8 & 105.8 & $1.10 \mathrm{E}-23$ \\
\hline DEC+X & -137.8 & 3 & 0.16 & 2.66 & 0 & -1.37 & 282.1 & 108.1 & $3.30 \mathrm{E}-24$ \\
\hline DEC & -154.9 & 2 & 0.83 & 5 & 0 & 0 & 314.1 & 140.1 & $3.80 \mathrm{E}-31$ \\
\hline BAYAREALIKE+X & -173.5 & 3 & 0.26 & 5 & 0 & -1.15 & 353.5 & 179.5 & $1.00 \mathrm{E}-39$ \\
\hline BAYAREALIKE & -225.3 & 2 & 0.38 & 0.98 & 0 & 0 & 454.7 & 280.7 & $1.10 \mathrm{E}-61$ \\
\hline
\end{tabular}


FIGURES

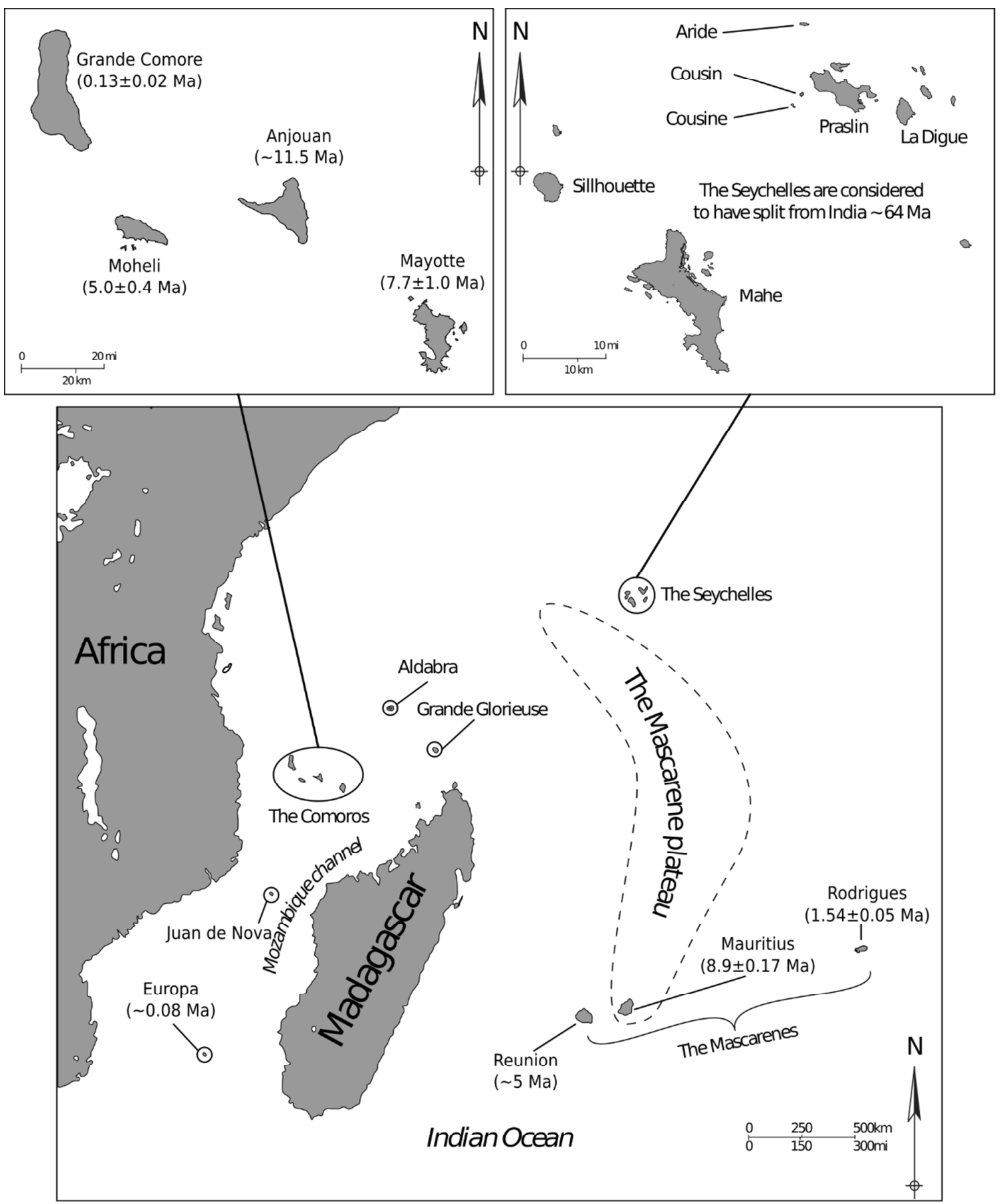

Fig. 1. The islands of the Southwest Indian Ocean area, with ages where known. Additionally marked is the Mascarene plateau, an area of shallow water that is likely to have been exposed multiple times during glacial periods. 
Fig. 2. The estimated biogeographic history of Cratopine weevils as inferred by BioGeoBEARS under the DEC $+\mathrm{J}+\mathrm{X}$ model using the BEAST2 MCC chronogram. Pie charts on nodes represent the relative probabilities of the inferred geographic range of the ancestral taxon represented by the node. Empty boxes on nodes represent inferred colonisations of Reunion from Mauritius while black boxes on nodes represent inferred colonisations of Mauritius from Reunion. Taxa with * after their label are flightless. 


\section{REFERENCES}

Alonso-Zarazaga, M.A. \& Lyal, C.H.C. (1999) A world catalogue of families and genera of Curculionoidea (Insecta: Coleoptera)(excepting Scolytidae and Platypodidae). Entomopraxis, Barcelona.

Bonneville, A., Barriot, J.P., \& Bayer, R. (1988) Evidence from geoid data of a hotspot origin for the southern Mascarene Plateau and Mascarene Islands (Indian Ocean). Journal of Geophysical Research, [Solid Earth], 93, 4199-4212.

Bouckaert, R., Heled, J., Kühnert, D., Vaughan, T., Wu, C.-H., Xie, D., Suchard, M.A., Rambaut, A., \& Drummond, A.J. (2014) BEAST 2: a software platform for Bayesian evolutionary analysis. PLoS computational biology, 10, e1003537.

Burnham, K.P. \& Anderson, D.R. (2002) Model Selection and Multimodel Inference: a Practical Information-Theoretic Approach. Springer, New York.

Casquet, J., Bourgeois, Y.X.C., Cruaud, C., Gavory, F., Gillespie, R.G., \& Thébaud, C. (2015) Community assembly on remote islands: a comparison of Hawaiian and Mascarene spiders. Journal of biogeography, 42, 39-50.

Cicconardi, F., Nardi, F., Emerson, B.C., Frati, F., \& Fanciulli, P.P. (2009) Deep phylogeographic divisions and long-term persistence of forest invertebrates (Hexapoda: Collembola) in the North-Western Mediterranean basin. Molecular ecology, 19, 386-400.

Darriba, D., Taboada, G.L., Doallo, R., \& Posada, D. (2012) jModelTest 2: more models, new heuristics and parallel computing. Nature methods, 9, 772.

Emerson, B.C. \& Gillespie, R.G. (2008) Phylogenetic analysis of community assembly and structure over space and time. Trends in ecology \& evolution, 23, 619-630.

Emerson, B.C. \& Kolm, N. (2005) Species diversity can drive speciation. Nature, 434, 10151017.

Emerson, B.C. \& Oromí, P. (2005) Diversification of the forest beetle genus Tarphius on the Canary Islands, and the evolutionary origins of island endemics. Evolution; international journal of organic evolution, 59, 586-598.

Faria, C., Machado, A., Amorim, I.R., Gage, M.J.G., Borges, P.A.V., \& Emerson, B.C. (2016) Evidence for multiple founding lineages and genetic admixture in the evolution of species within an oceanic island weevil (Coleoptera, Curculionidae) super-radiation. Journal of biogeography, 43, 178-191.

Harrison, R.G. (1980) Dispersal Polymorphisms in Insects. Annual review of ecology and systematics, 11, 95-118.

Heaney, L.R. (2007) Is a new paradigm emerging for oceanic island biogeography? Journal of biogeography, 34, 753-757.

Huelsenbeck, J.P. \& Ronquist, F. (2001) MRBAYES: Bayesian inference of phylogenetic trees. Bioinformatics , 17, 754-755.

Hustache, A. (1919) Synopsis des Curculionides de la faune malgache. I. Brachydérides et Otiorrhynchides. Annales de la Societe entomologique de France. Societe entomologique de France, 87, 441-520. 
Ikeda, H., Nishikawa, M., \& Sota, T. (2012) Loss of flight promotes beetle diversification. Nature communications, 3, 648 .

Katoh, K., Misawa, K., Kuma, K.-I., \& Miyata, T. (2002) MAFFT: a novel method for rapid multiple sequence alignment based on fast Fourier transform. Nucleic acids research, 30, 30593066.

Kitson, J.J.N., Warren, B.H., Florens, F.B.V., Baider, C., Strasberg, D., \& Emerson, B.C. (2013) Molecular characterization of trophic ecology within an island radiation of insect herbivores (Curculionidae: Entiminae: Cratopus). Molecular ecology, 22, 5441-5455.

Landis, M.J., Matzke, N.J., Moore, B.R., \& Huelsenbeck, J.P. (2013) Bayesian analysis of biogeography when the number of areas is large. Systematic biology, 62, 789-804.

MacArthur, R.H. \& Wilson, E.O. (1963) An Equilibrium Theory of Insular Zoogeography. Evolution; international journal of organic evolution, 17, 373-387.

MacArthur, R.H. \& Wilson, E.O. (1967) The Theory of Island Biogeography. Princeton University Press,

Machado, A., López, M., Almeida, T., \& Hernández, M. (2008) Mitochondrial DNA phylogenetic analysis of the genus Laparocerus (Coleoptera: Curculionidae: Entiminae). I. The Madeiran clade. Zoologica scripta, 37, 415-427.

Matzke, N.J. (2013) Probabilistic historical biogeography: new models for founder-event speciation, imperfect detection, and fossils allow improved accuracy and model-testing. Frontiers of Biogeography, 5, 242-248.

Matzke, N.J. (2014) Model selection in historical biogeography reveals that founder-event speciation is a crucial process in Island Clades. Systematic biology, 63, 951-970.

McDougall, I. (1971) Geochronology and evolution of the young volcanic island of Reunion, Indian Ocean. Geochimica et cosmochimica acta, 35, 261-\&.

McDougall, I., Upton, B.G.J., \& Wadsworth, W.J. (1965) A geological reconnaissance of Rodriguez Island, Indian Ocean. Nature, 206, 26-27.

Medeiros, M.J. \& Gillespie, R.G. (2011) Biogeography and the evolution of flightlessness in a radiation of Hawaiian moths (Xyloryctidae: Thyrocopa). Journal of biogeography, 38, 101111.

Meseguer, A.S., Aldasoro, J.J., \& Sanmartín, I. (2013) Bayesian inference of phylogeny, morphology and range evolution reveals a complex evolutionary history in St. John's wort (Hypericum). Molecular phylogenetics and evolution, 67, 379-403.

Montaggioni, L.F. \& Nativel, P. (1988) La Reunion, Ile Maurice: Geologie et apercus biologiques, plantes et animaux. Masson, France.

Moore, J., White, W.M., Paul, D., Duncan, R.A., Abouchami, W., \& Galer, S.J.G. (2011) Evolution of shield-building and rejuvenescent volcanism of Mauritius. Journal of Volcanology and Geothermal Research, 207, 47-66.

Nylander, J.A.A., Wilgenbusch, J.C., Warren, D.L., \& Swofford, D.L. (2007) AWTY (are we there yet?): a system for graphical exploration of MCMC convergence in Bayesian phylogenetics. Bioinformatics , 24, 581-583. 
Rambaut, A. \& Drummond, A.J. (2007) Tracer v1.5.0 available from http://tree.bio.ed.ac.uk/software/tracer/.

R Development Core Team (2017) R: A Language and Environment for Statistical Computing. $\mathrm{R}$ Foundation for Statistical Computing, Vienna, Austria.,

Ree, R.H. \& Sanmartin, I. (2018) Conceptual and statistical problems with the DEC+J model of founder-event speciation and its comparison with DEC via model selection. Journal of biogeography, .

Ree, R.H. \& Smith, S.A. (2008) Maximum likelihood inference of geographic range evolution by dispersal, local extinction, and cladogenesis. Systematic biology, 57, 4-14.

Roff, D.A. (1990) The evolution of flightlessness in insects. Ecological monographs, 60, 389-421.

Ronquist, F. \& Cannatella, D. (1997) Dispersal-Vicariance Analysis: A New Approach to the Quantification of Historical Biogeography. Systematic biology, 46, 195-203.

Samuelson, G.A. (2003) Review of Rhyncogonus of the Hawaiian Islands. Bishop Museum Bulletins in Entomology, 11, 1-107.

Sattler, K. (1991) A review of wing reduction in Lepidoptera. Bulletin of the British Museum, 60, .

Stamatakis, A., Hoover, P., \& Rougemont, J. (2008) A rapid bootstrap algorithm for the RAxML Web servers. Systematic biology, 57, 758-771.

Strijk, J.S., Bone, R.E., Thébaud, C., Buerki, S., Fritsch, P.W., Hodkinson, T.R., \& Strasberg, D. (2014) Timing and tempo of evolutionary diversification in a biodiversity hotspot: Primulaceae on Indian Ocean islands. Journal of biogeography, 41, 810-822.

Thébaud, C., Warren, B.H., Strasberg, D., \& Cheke, A. (2009) Mascarene Islands, biology. Encyclopedia of Islands (ed. by R.G. Gillespie and D.A. Clague), pp. 612-619. University of California Press, Berkeley.

Van Dam, M.H. \& Matzke, N.J. (2016) Evaluating the influence of connectivity and distance on biogeographical patterns in the south-western deserts of North America. Journal of biogeography, 43, 1514-1532.

Voisin, J.-F. \& Poussereau, J. (2009) A propos de Cratopus nanus et de Cratopus parvus de lîle de la Réunion (Coleoptera, Curculionidae). Nouvelle Revue d'Entomologie, 26, 59-65.

Warren, B.H., Safford, R.J., Strasberg, D., \& Thébaud, C. (2013) Bird biogeography and evolution in the Malagasy region. The Birds of Africa: Volume VIII: The Malagasy Region: Madagascar, Seychelles, Comoros, Mascarenes (ed. by R. Safford, F. Hawkins, and J. Gale), pp. 35-36. A\&C Black, London.

Warren, B.H., Strasberg, D., Bruggemann, J.H., Prys-Jones, R.P., \& Thébaud, C. (2010) Why does the biota of the Madagascar region have such a strong Asiatic flavour? Cladistics: the international journal of the Willi Hennig Society, 26, 526-538.

Whittaker, R.J., Triantis, K.A., \& Ladle, R.J. (2008) A general dynamic theory of oceanic island biogeography. Journal of biogeography, 35, 977-994.

Williams, J.R. (2000) A revision of the Mascarene weevil genus Syzygops Schonherr (Coleoptera : Curculionidae : Entiminae). Invertebrate Taxonomy, 14, 411-432. 
Williams, J.R. \& Cox, M.L. (2003) A contribution to the study of Mascarene Weevils of the genus Cratopus Schonherr (Coleoptera: Curculionidae: Entiminae: Cratopini): The species of Mauritius and Rodrigues. The Mauritius Institute Bulletin, 12, 1-67.

Wright, N.A., Steadman, D.W., \& Witt, C.C. (2016) Predictable evolution toward flightlessness in volant island birds. Proceedings of the National Academy of Sciences of the United States of America, 113, 4765-4770.

Xia, X., Xie, Z., Salemi, M., Chen, L., \& Wang, Y. (2003) An index of substitution saturation and its application. Molecular phylogenetics and evolution, 26, 1-7.

Yu, G., Smith, D.K., Zhu, H., Guan, Y., \& Lam, T.T.-Y. (2017) ggtree: an r package for visualization and annotation of phylogenetic trees with their covariates and other associated data. Methods in ecology and evolution, 8, 28-36.

\section{BIOSKETCH}

JJNK undertook most of the beetle sampling and performed all the laboratory work and data analyses. BHW and DS contributed to the fieldwork. JJNK and BCE wrote the manuscript. All authors discussed the results and commented on the manuscript. This project was conceived by BCE, DS and CT. It was supervised primarily by BCE and secondarily by BHW.

\section{SUPPORTING INFORMATION}

Additional Supporting Information may be found in the online version of this article: Appendix S1: Molecular methods and results for definition of OTUs. Appendix S2: Gene trees and summary information for each locus used in the main phylogeny.

GitHub repository: https://github.com/James-Kitson/Biogeography <doi will be provided upon acceptance>. This repository includes all scripts used for plotting and analysing trees.

\section{DATA ACCESSIBILITY}

All sequences used in this manuscript are available under GenBank accession numbers $<$ These will be provided upon acceptance>. All plotting scripts are available in our GitHub repository. 
Journal of Biogeography
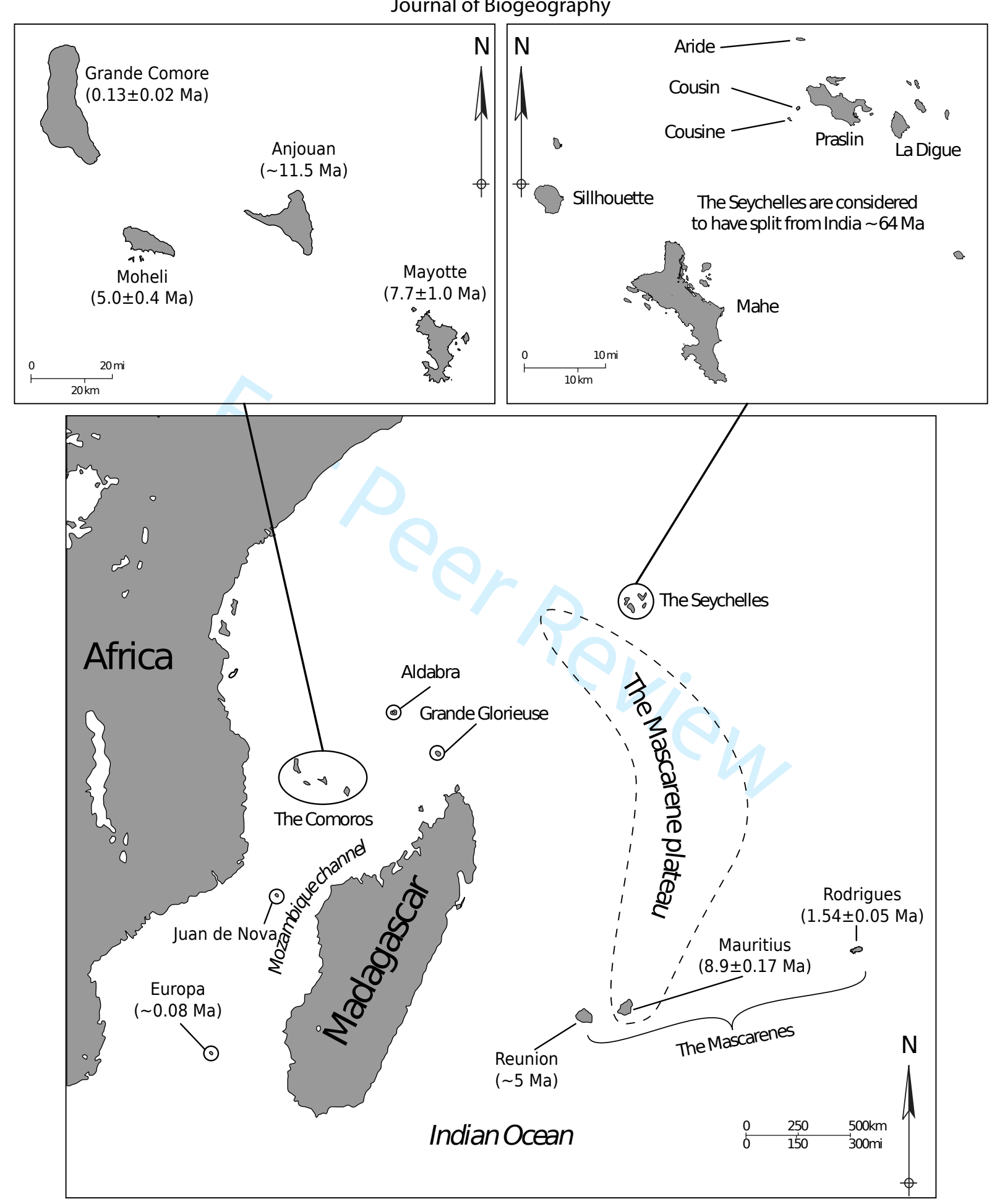


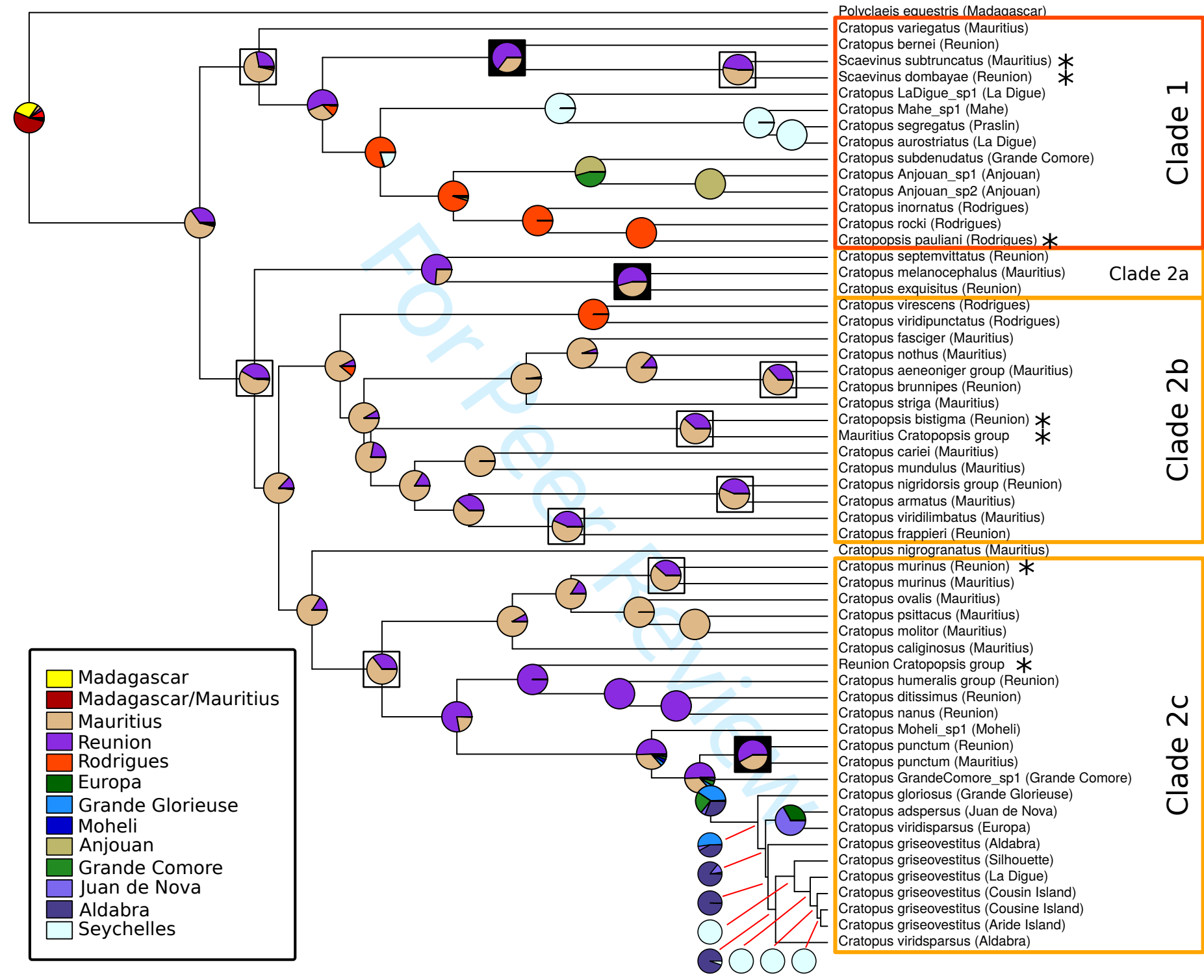


Journal of Biogeography

SUPPORTING INFORMATION

\section{Community assembly and diversification in a species-rich radiation of island weevils (Coleoptera: Cratopini)}

James J. N. Kitson, Ben H. Warren, Christophe Thébaud, Dominique Strasberg and Brent C. Emerson

\section{Appendix S1: Methods and results for molecular methods and OTU definitions used in the main manuscript.}

\section{S1.1 Introduction}

The purpose of the methods and results presented here is to describe methods used to define the operational taxonomic units (OTUs) used for figure 2 in the main manuscript and to give further detail in the molecular methods used throughout.

\section{S1.2 Study sites and reference list used for the identification of samples}

Specimens were collected from the islands of the Southwest Indian Ocean by foliage beating during wet seasons between June 2007 and December 2011. Samples were placed directly in $99 \%$ ethanol. Sampling sites were recorded with handheld GPS units. Samples were identified to taxonomic species using morphological keys for Cratopus and Cratopopsis provided by Jaques Poussereau (unpublished work) and the original descriptions of most species (Hustache 1919, 1920; Richard 1957, 1958, 1961, 1977, 1995a, b; Vinson 1967; Ferragu \& Richard 1990, 1993; Williams \& Cox 2003; Voisin \& Poussereau 2007a, b, 2009; Poussereau \& Voisin 2009; Galman et al. 2011). Once identified, up to five individuals of each taxonomically described species were chosen from every site in which they were collected. See table S1.2.1 for locality information. 
Table S1.2.1: GPS co-ordinates for localities used in this study

\begin{tabular}{|c|c|c|c|}
\hline Island & Site & Latitude & Longtitude \\
\hline La Réunion & Basse Vallee & -21.3510 & 55.7020 \\
\hline La Réunion & Bayonne & -21.2210 & 55.4630 \\
\hline La Réunion & Bois Ozoux & -21.1980 & 55.6480 \\
\hline La Réunion & Cap Blanc & -21.2770 & 55.6610 \\
\hline La Réunion & Cap Jaune & -21.3780 & 55.6770 \\
\hline La Réunion & Cap Mechant & -21.3760 & 55.7090 \\
\hline La Réunion & Cascade du Chien & -21.0330 & 55.6100 \\
\hline La Réunion & Col de Bellevue & -21.1660 & 55.5910 \\
\hline La Réunion & Colorado & -20.9050 & 55.4280 \\
\hline La Réunion & Etang du Gol & -21.2840 & 55.3910 \\
\hline La Réunion & Etang St Paul & -20.9960 & 55.2950 \\
\hline La Réunion & Foret de Bebour & -21.1200 & 55.5680 \\
\hline La Réunion & Foret de Bel Air & -21.3070 & 55.6020 \\
\hline La Réunion & Foret de Tevelave & -21.1840 & 55.3750 \\
\hline La Réunion & Foret dominale de la cote sous le Vent & -21.2820 & 55.3630 \\
\hline La Réunion & Foret dominale Notre Dame de la Paix & -21.2640 & 55.6030 \\
\hline La Réunion & Foret du Volcane & -21.2060 & 55.6050 \\
\hline La Réunion & Grand Etang & -21.0960 & 55.6490 \\
\hline La Réunion & Grande Coude & -21.2780 & 55.6310 \\
\hline La Réunion & Gros Piton Rond & -21.1550 & 55.5980 \\
\hline La Réunion & Hell Bourg & -21.0730 & 55.5210 \\
\hline La Réunion & La Ravine de la Grande Chaloupe & -20.9280 & 55.3880 \\
\hline La Réunion & Le Block & -21.1310 & 55.4950 \\
\hline La Réunion & Le Maido & -21.0700 & 55.3870 \\
\hline La Réunion & Le Tampon & -21.2810 & 55.5170 \\
\hline La Réunion & Les Makes & -21.1850 & 55.4330 \\
\hline La Réunion & Mare Longue & -21.3500 & 55.7430 \\
\hline La Réunion & Nez de Boeuf & -21.2030 & 55.6190 \\
\hline La Réunion & Pic Adam & -20.9460 & 55.4650 \\
\hline La Réunion & Piton de Grande Anse & -21.3730 & 55.5510 \\
\hline La Réunion & Piton de l'eau & -21.1750 & 55.6850 \\
\hline La Réunion & Piton Desforges & -21.1960 & 55.5750 \\
\hline La Réunion & Piton Enchaing & -21.0440 & 55.5000 \\
\hline La Réunion & Piton Hyacinthe & -21.2180 & 55.5370 \\
\hline La Réunion & Piton Mahot & -21.2250 & 55.5860 \\
\hline La Réunion & Piton Textor & -21.1850 & 55.6310 \\
\hline La Réunion & Plaine d'Affouches & -20.9830 & 55.4030 \\
\hline La Réunion & Plaine des Chicots & -20.9800 & 55.4460 \\
\hline La Réunion & Plaine des Fougiers & -20.9800 & 55.5050 \\
\hline
\end{tabular}




\begin{tabular}{|c|c|c|c|}
\hline La Réunion & Plaine des Gregues & -21.3260 & 55.6100 \\
\hline La Réunion & Plaine des Lianes & -21.0540 & 55.5760 \\
\hline La Réunion & Plaine des Tamarinds & -21.0790 & 55.4430 \\
\hline La Réunion & Ravine Jean Payet & -21.2970 & 55.5270 \\
\hline La Réunion & Route de Plaine de les Fougiers & -20.9800 & 55.5220 \\
\hline La Réunion & Route des Tamarinds & -21.0590 & 55.3660 \\
\hline La Réunion & Route forrestiere du Maido & -21.0566 & 55.3634 \\
\hline La Réunion & Sentier Trophee Mondial & -21.2000 & 55.4930 \\
\hline La Réunion & Site Dior & -20.9990 & 55.5670 \\
\hline La Réunion & Takamaka & -21.0940 & 55.6090 \\
\hline La Réunion & Trois Bassins & -21.1180 & 55.3610 \\
\hline La Réunion & Vallee Heureuse & -21.3290 & 55.6970 \\
\hline La Réunion & Volcano & -21.2180 & 55.6870 \\
\hline Mauritius & Brise Fer & -20.3780 & 57.4420 \\
\hline Mauritius & Camp & -20.3756 & 57.4441 \\
\hline Mauritius & Camp Thorel & -20.2090 & 57.6390 \\
\hline Mauritius & Chamarel & -20.4300 & 57.3740 \\
\hline Mauritius & Corps de Garde & -20.2490 & 57.4510 \\
\hline Mauritius & Ebony Forest & -20.4317 & 57.3727 \\
\hline Mauritius & Florin & unknown & unknown \\
\hline Mauritius & Gorges & -20.4040 & 57.4320 \\
\hline Mauritius & Ile Marianne & -20.3800 & 57.7870 \\
\hline Mauritius & Ille aux Vacoas & -20.3980 & 57.7700 \\
\hline Mauritius & Ille de la Passe & -20.3990 & 57.7670 \\
\hline Mauritius & Illot Sancho & -20.5040 & 57.4490 \\
\hline Mauritius & Kanaka & -20.4060 & 57.5190 \\
\hline Mauritius & Le Pouce & -20.1980 & 57.5290 \\
\hline Mauritius & L'Etoiles & -20.3230 & 57.6700 \\
\hline Mauritius & Lion Mountain & -20.3620 & 57.7250 \\
\hline Mauritius & Machabee & -20.3960 & 57.4560 \\
\hline Mauritius & Mondrain & -20.3250 & 57.4550 \\
\hline Mauritius & Montagne Camizard & -20.3360 & 57.7150 \\
\hline Mauritius & Montagne Cocotte & -20.4400 & 57.4670 \\
\hline Mauritius & Montagne de Belle Ombre & -20.4670 & 57.4170 \\
\hline Mauritius & Petrin & -20.4080 & 57.4730 \\
\hline Mauritius & Pidgeon wood & -20.4410 & 57.4870 \\
\hline Mauritius & Plaine Champagne & -20.4190 & 57.4450 \\
\hline Mauritius & Plaine des Roches & -20.1237 & 57.7423 \\
\hline Mauritius & Pointe de Roche Noire & -20.1089 & 57.7462 \\
\hline Mauritius & Roches Noires & -20.1055 & 57.7323 \\
\hline Mauritius & Round Island & -19.8520 & 57.7880 \\
\hline
\end{tabular}




\section{S1.3 DNA extraction, PCR amplification and sequencing for the definition of OTUs}

DNA was extracted from the head and pronotum using the DNeasy 96 well Blood and Tissue Extraction kit (QIAGEN, West Sussex, UK) with the digestion buffer volumes amended for large specimens as recommended by the manufacturer. The primers COIICraF and COIICraR (see Table S1.6.1) were used to amplify the mitochondrial gene Cytochrome Oxidase II (COII). Amplification conditions were; $0.5 \mathrm{mM}$ of each primer, $5 \mathrm{mM} \mathrm{MgCl}_{2}$ and a thermal profile of: $95^{\circ} \mathrm{C}$ for $60 \mathrm{~s}, 58^{\circ} \mathrm{C}$ for $60 \mathrm{~s}$ and $72^{\circ} \mathrm{C}$ for $90 \mathrm{~s}, 40$ cycles.

Sequencing reactions were performed with the Big Dye Terminator v3.1 Cycle Sequencing kit (Applied Biosystems, California, USA). COIICraF was used for forward sequencing and COIICraR was used for reverse sequencing when forward sequences of less than $600 \mathrm{bp}$ were produced. When reverse sequencing was employed, the consensus of each pair of forward and reverse sequences was generated in Geneious Pro version 5.6 (Drummond et al. 2012). The thermal profile used for sequencing reactions was: $96^{\circ} \mathrm{C}$ for $10 \mathrm{~s}, 58^{\circ} \mathrm{C}$ for $5 \mathrm{~s}$ and $60^{\circ} \mathrm{C}$ for $240 \mathrm{~s}, 25$ cycles. Sequences were read on a 3730XL sequencer (Applied Biosystems). All sequences were checked in Geneious Pro version 5.4. Sequences were aligned using MAFFT v6.814b (Katoh et al. 2002) with the following parameter values: scoring matrix $1 \mathrm{PAM} / \mathrm{k}=2$, Gap open penalty $=1.53$, Offset value $=0.123$, and then checked by eye .

\section{S1.4 Phylogenetic analyses and definition of OTUs}

A maximum likelihood tree was generated using RAxML version 7.7.1 (Stamatakis et al. 2008) using RAxML BlackBox (https://embnet.vital-it.ch/raxml-bb/index.php) to assess the clustering of individuals with respect to their taxonomic assignment. Operational taxonomic units were defined as the minimal monophyletic group containing samples belonging to a single taxonomically described species or set of taxonomically described species. For example, if any single taxonomically described species was paraphyletic with regard to mtDNA relationships among individuals then a monophyletic OTU was created from all other taxonomically described species sharing the same common ancestor as the paraphyletic species. In this way, the OTUs represent taxonomic uncertainty, with the objective of underestimating rather than overestimating species number. 


\section{S1.5 Results for definition of OTUs}

Of the 915 beetles selected for sequencing, 909 were successfully amplified and sequenced for COII with 397 samples that required reverse sequencing (a 99.3\% success rate) yielding sequences from $536 \mathrm{bp}$ to $663 \mathrm{bp}$ with a mean length of $653.1 \mathrm{bp}$ and a standard deviation of $19.0 \mathrm{bp}$. Five hundred and ninety-seven unique sequences were recovered from across 76 taxonomically described species with an average pairwise p-distance of $14.0 \%$, a maximum of $24.0 \%$ and a standard deviation of 3.5\%. Figure S1.5.1 shows the Maximum Likelihood tree generated with samples colour coded by island. Yellow stars have been used to indicate samples of $C$. caliginosus that are recovered within the $C$. murinus clade and separately from the remaining $C$. caliginosus samples. As these taxonomically described species are distinct from each other, misidentification of the samples is unlikely. The position of these C. caliginosus samples may be due to hybridisation between $C$. caliginosus and $C$. murinus but further nuclear markers would be necessary in order to confirm this. The identified OTUs are mapped on to figure S1.5.2. 


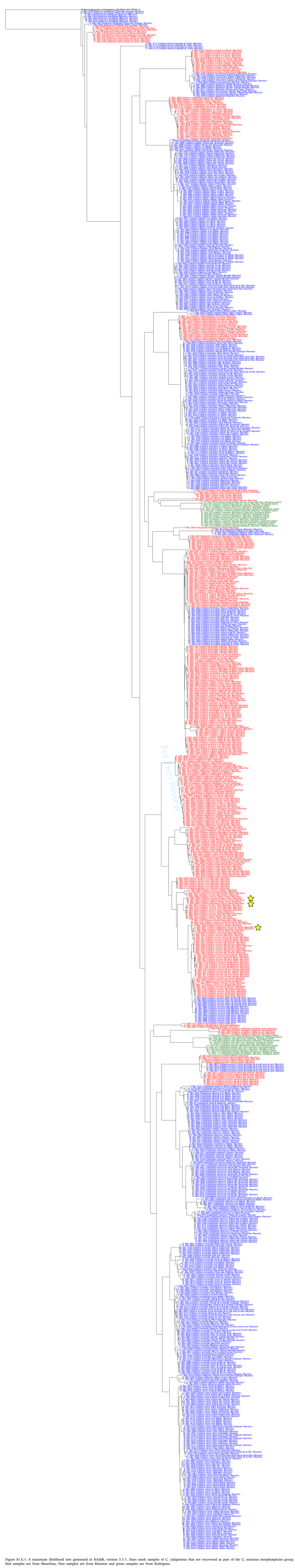




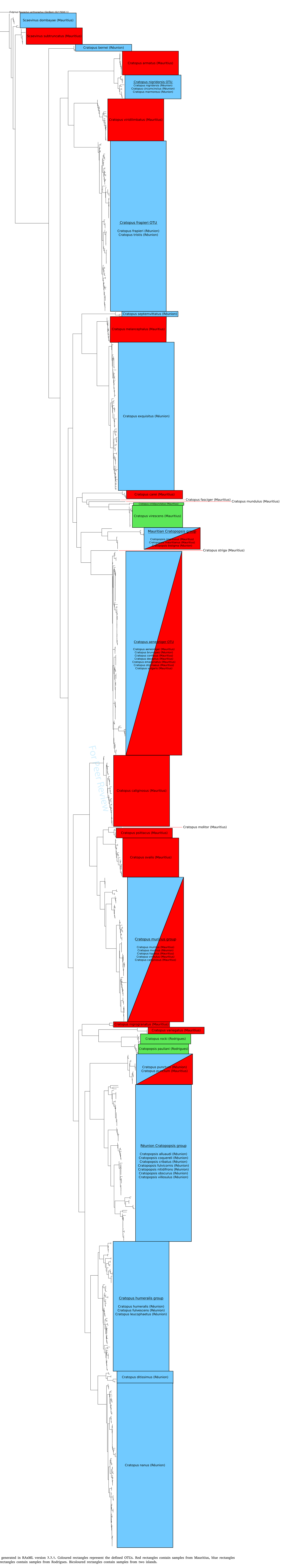




\section{S1.6: DNA extraction, PCR amplification and sequencing of nuclear loci}

Based on clustering of COII sequences, individuals were chosen for the amplification and DNA sequencing of three additional loci: Arginine Kinase (ArgK), Histone 3 and the ribosomal gene 28S. Both ArgK and Histone 3 were amplified with a nested PCR. For ArgK a first amplification was performed with the primers ArgKforB2 and ArgKrevB1 [both attributed to Danforth et al. (2005) in McKenna et al. (2009)] with $0.5 \mathrm{mM}$ of each primer, $5 \mathrm{mM} \mathrm{MgCl}_{2}$ and a thermal profile of: $95^{\circ} \mathrm{C}$ for $60 \mathrm{~s}, 50^{\circ} \mathrm{C}$ for $60 \mathrm{~s}$ and $72^{\circ} \mathrm{C}$ for $120 \mathrm{~s}, 37$ cycles. $1 \mu$ of the PCR product was then used as template for a second PCR with the primers ArgK_F1_semidg and ArgK_R2_fulldg with 0.5 $\mathrm{mM}$ of each primer, $4.3 \mathrm{mM} \mathrm{MgCl} 2$ and a thermal profile of: $95^{\circ} \mathrm{C}$ for $60 \mathrm{~s}, 57^{\circ} \mathrm{C}$ for $60 \mathrm{~s}$ and $72^{\circ} \mathrm{C}$ for 120 s, 37 cycles, and PCR products were sequenced with ArgK_F1_semidg. For Histone 3 a first amplification was performed with M13REVH3AF and M13(-21)H3AR, primers modified from Colgan et al. (1998), these are the primers listed in with M13 tails to improve PCR yield (Regier \& Shi 2005). The thermal profile for Histone 3 employed a touchdown protocol (Don et al. 1991) of $94^{\circ} \mathrm{C}$ for $60 \mathrm{~s}, 60^{\circ} \mathrm{C}$ for $60 \mathrm{~s}$ and $72^{\circ} \mathrm{C}$ for $120 \mathrm{~s}$ (touched down by $1^{\circ} \mathrm{C}$ per cycle), 5 cycles, followed by 35 cycles with an annealing temperature of $55^{\circ} \mathrm{C}$ with $0.5 \mathrm{mM}$ of each primer, $5 \mathrm{mM} \mathrm{MgCl}_{2}$ and PCR products were separated on an agarose gel and a target band of approximately 330bp sampled with a pipette tip. Tips were then soaked in $10 \mu \mathrm{l} \mathrm{of} \mathrm{H}_{2} \mathrm{O}$ for 20 minutes to release PCR product, and $1 \mu \mathrm{l}$ of the resulting solution used as the template for a second PCR with the primers H3AF and H3AR, and the thermal profile of the first PCR. Sequencing was carried out in both directions using H3AF and H3AR. 28S was amplified using the primers 28SDD and 28SFF (Ahrens et al. 2007) with $0.5 \mathrm{mM}$ of each primer, $2 \mathrm{mM} \mathrm{MgCl} 2$ and a thermal profile of: $94^{\circ} \mathrm{C}$ for $60 \mathrm{~s}, 50^{\circ} \mathrm{C}$ for $30 \mathrm{~s}$ and $72^{\circ} \mathrm{C}$ for $30 \mathrm{~s}, 31$ cycle, and PCR products were then sequenced with 28SDD. Sequences for all primers used can be found in Table S1.6.1. DNA sequences were read on a 3730XL sequencer (Applied Biosystems).

All sequences were checked, and in the case of reverse sequencing, consensus sequences generated with Geneious Pro version 5.6 (Drummond et al. 2012). Sequences were aligned using MAFFT v6.814b (Katoh et al. 2002) with the following parameter values: scoring matrix $1 \mathrm{PAM} / \mathrm{k}=2$, Gap open penalty $=1.53$, Offset value $=0.123$, and then checked by eye. The aligned sequences were tested for saturation using the entropy-based index of substitution saturation (Xia et al. 2003) as implemented in DAMBE v5.2.78 (Xia \& Xie 2001). This was performed on two data sets, one comprised of the first and second codon positions and the second comprised of the third codon positions, with the exception of $28 \mathrm{~S}$ which was not partitioned.

Table S1.6.1: Primers used in this study.

\begin{tabular}{|c|c|c|c|}
\hline Primer & Direction & Locus & Sequence (5'-3') \\
\hline COIICraF & Forward & COII & TAATATGGCAGAWTAGTGCAATGGA \\
\hline COIICraR & Reverse & COII & TGCTTTCAGTCATCTAATGATCTRTTTACAGA \\
\hline ArgKforB2 & Forward & ArgK & GAYTCCGGWATYGGWATCTAYGCTCC \\
\hline ArgKrevB1 & Reverse & ArgK & TCNGTRAGRCCCATWCGTCTC \\
\hline ArgK_F1_semidg & Forward & ArgK (nested) & GATCCCATCATHGARGAYTARCA \\
\hline ArgK_R2_fulldg & Reverse & ArgK (nested) & GTNCCYAARTTNGTNGGRCARAA \\
\hline M13REVH3AF & Forward & H3 & CAGGAAACAGCTATGACCATGGCTCGTACCAAGCAGACVGC \\
\hline M13(-21)H3AR & Reverse & H3 & TGTAAAACGACGGCCAGTATATCCTTRGGCATRATRGTGAC \\
\hline H3AF & Forward & H3 (nested) & ATGGCTCGTACCAAGCAGACVGC \\
\hline H3AR & Reverse & H3 (nested) & ATATCCTTRGGCATRATRGTGAC \\
\hline 28SDD & Forward & $28 \mathrm{~S}$ & GGGACCCGTCTTGAAACAC \\
\hline 28SFF & Reverse & $28 \mathrm{~S}$ & TTACACACTCCTTAGCGGAT \\
\hline
\end{tabular}




\section{References}

Ahrens, D., Monaghan, M.T. \& Vogler, A.P. (2007). DNA-based taxonomy for associating adults and larvae in multi-species assemblages of chafers (Coleoptera: Scarabaeidae). Mol. Phylogenet. Evol., 44, 436-449.

Colgan, D.J., McLauchlan, A., Wilson, G.D.F., Livingston, S.P., Edgecombe, G.D., Macaranas, J., et al. (1998). Histone H3 and U2 snRNA DNA sequences and arthropod molecular evolution. Aust. J. Zool., 46, 419-437.

Danforth, B.N., Lin, C.-P. \& Fang, J. (2005). How do insect nuclear ribosomal genes compare to protein-coding genes in phylogenetic utility and nucleotide substitution patterns? Syst. Entomol., 30, 549-562.

Don, R.H., Cox, P.T., Wainwright, B.J., Baker, K. \& Mattick, J.S. (1991). “Touchdown” PCR to circumvent spurious priming during gene amplification. Nucleic Acids Res., 19, 4008.

Drummond, A.J., Ashton, B., Buxton, S., Cheung, M., Cooper, A., Duran, C., et al. (2012). Geneious v5.6, available from http://www.geneious.com/.

Ferragu, M. \& Richard, R. (1990). Trois nouveaux Curculionides de Madagascar et de l'Île de la Réunion (Coleoptera). Nouv. Rev. Entomol., 12, 105-110.

Ferragu, M. \& Richard, R. (1993). Etude portant sur les Cratopus de l'Ile de la Réunion (Coleoptera: Curculionidae). Revue Française d'Entomologie (N.S.), 14, 111-116.

Galman, G., Matyot, P. \& Voisin, J.-F. (2011). Le genre Cratopus aux îles Seychelles (Coleoptera: Curculionidae). Annales de la Société entomologique de France (N.S.), 47, 229-240.

Hustache, A. (1919). Synopsis des Curculionides de la faune malgache. I. Brachydérides et Otiorrhynchides. Ann. Soc. Entomol. Fr., 87, 441-520.

Hustache, A. (1920). Curculionides des Iles Mascareignes. Extrait des Annales de la Societe Entomologique de France, 89, 113-203.

Katoh, K., Misawa, K., Kuma, K.-I. \& Miyata, T. (2002). MAFFT: a novel method for rapid multiple sequence alignment based on fast Fourier transform. Nucleic Acids Res., 30, 3059-3066.

McKenna, D.D., Sequeira, A.S., Marvaldi, A.E. \& Farrell, B.D. (2009). Temporal lags and overlap in the diversification of weevils and flowering plants. Proc. Natl. Acad. Sci. U. S. A., 106, 70837088.

Poussereau, J. \& Voisin, J.-F. (2009). Cratopus francki, espèce nouvelle de la Réunion (Coleoptera, Curculionidae). Bull. Soc. Entomol. France, 114, 361-364.

Regier, J.C. \& Shi, D. (2005). Increased yield of PCR product from degenerate primers with nondegenerate, nonhomologous 5' tails. Biotechniques, 38, 34, 36, 38.

Richard, R. (1957). Coléoptères Curculionidae de La Réunion. Mémoires de l'Institut Scientifique de Madagascar, (E), 8, 59-94.

Richard, R. (1958). Curculionides nouveaux ou mal connus des Comores, ile Glorieuse, ile Europa New or little known Curculionidae from the Comoro Islands, Glorioso Island and Europa Island. Mémoires de l'Institut Scientifique de Madagascar, (E), 10, 41-63.

Richard, R. (1961). Notes sur quelques Curculionides de l'ile Rodriguez. The Mauritius Institute Bulletin, 5, 213-220.

Richard, R. (1977). Nouveaux Curculionides des iles Europa et de la Réunion. Bull. Soc. Entomol. France, 82, 125-127.

Richard, R. (1995a). Description de deux Cratopini nouveaux de la région Malgache [Coleoptera: Curculionidae]. Nouv. Rev. Entomol., 17, 63-65.

Richard, R. (1995b). Note sur l'apparition brusque d'une variation importante de la squamulation de Cratopus humeralis Boheman (Coleoptera: Curculionidae). Bull. Soc. Entomol. France, 100, 303-306.

Stamatakis, A., Hoover, P. \& Rougemont, J. (2008). A rapid bootstrap algorithm for the RAxML Web servers. Syst. Biol., 57, 758-771.

Vinson, J. (1967). Liste Chorologique des Coleopteres des Mascareignes. The Mauritius Institute Bulletin, 4, 299-357.

Voisin, J.-F. \& Poussereau, J. (2007a). Charactérisation de Cratopus frappieri Deyrolle, 1862 (Coleoptera, Curculionidae). Nouv. Rev. Entomol., 24, 329-334. 
Voisin, J.-F. \& Poussereau, J. (2007b). L'identité de Cratopus sumptuosus Boheman, 1834, de Cratopus exquisitus Boheman, 1840, et de Cratopus sandi Deyrolle, 1862, espèces endémiques de l'île de la Réunion (Coleoptera, Curculionidae). Nouv. Rev. Entomol., 24, 279-283.

Voisin, J.-F. \& Poussereau, J. (2009). A propos de Cratopus nanus et de Cratopus parvus de l'île de la Réunion (Coleoptera, Curculionidae). Nouv. Rev. Entomol., 26, 59-65.

Williams, J.R. \& Cox, M.L. (2003). A contribution to the study of Mascarene Weevils of the genus Cratopus Schonherr (Coleoptera: Curculionidae: Entiminae: Cratopini): The species of Mauritius and Rodrigues. The Mauritius Institute Bulletin, 12, 1-67.

Xia, X. \& Xie, Z. (2001). DAMBE: software package for data analysis in molecular biology and evolution. J. Hered., 92, 371-373.

Xia, X., Xie, Z., Salemi, M., Chen, L. \& Wang, Y. (2003). An index of substitution saturation and its application. Mol. Phylogenet. Evol., 26, 1-7. 
Scaevinus subtruncatus (Mauritius) Scaevinus subtruncatus (Mauritius
Scaevinus dombayae (La Réunion)

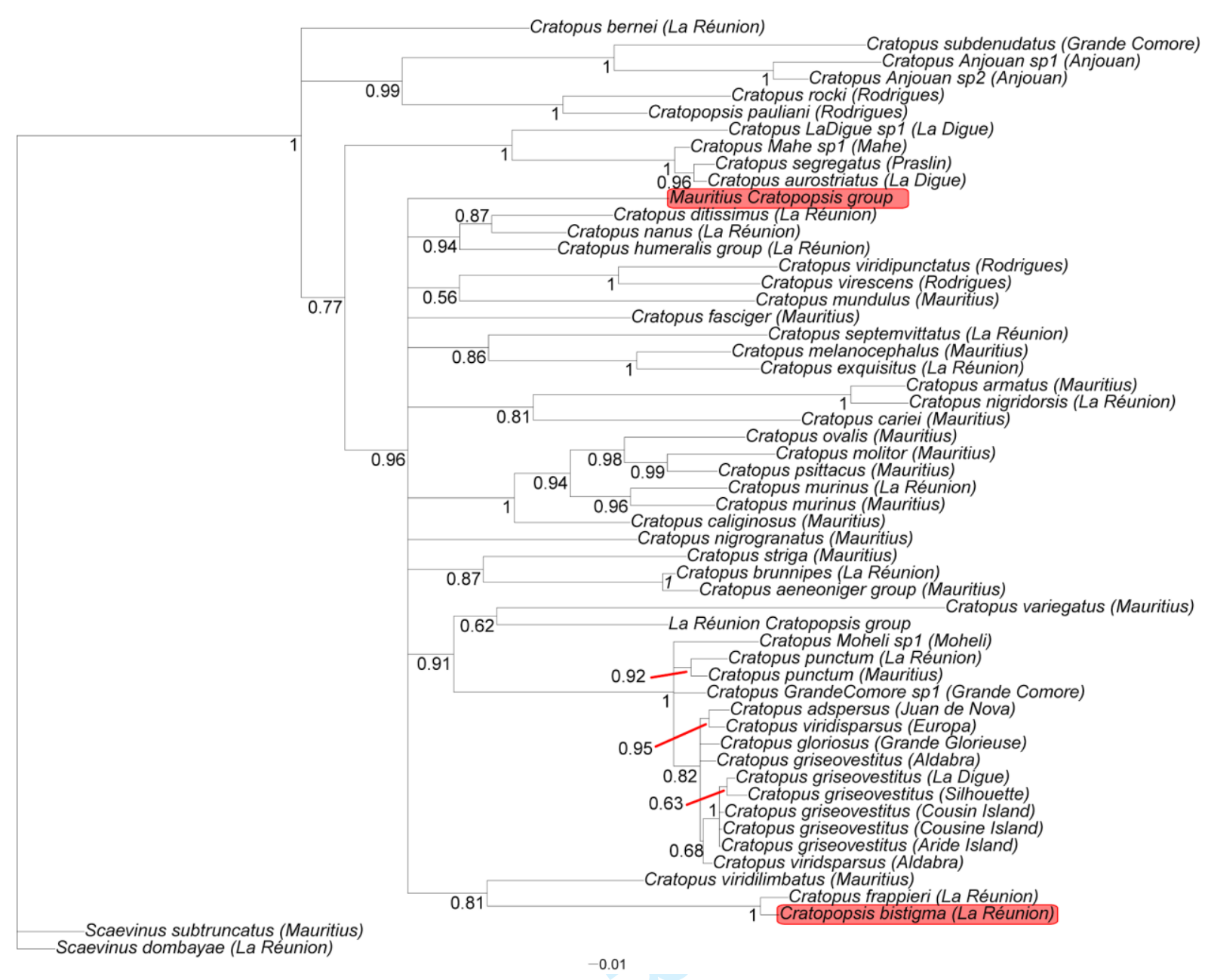

Fig S2.3: A Bayesian inference tree generated by MrBayes using an alignment of Cratopine COII sequences. Values placed on nodes represent Bayesian posterior probabilities for that node. Cratopopsis bistigma and Cratopopsis mauritianus are highlighted to show incongruence between nuclear loci and COII. 
Fig S2.4: A Bayesian inference tree generated by Mr Bayes using an alignment of Cratopine ArgK sequences. Values placed on nodes represent Bayesian posterior probabilities for that node. Cratopopsis bistigma and Cratopopsis mauritianus are highlighted to show incongruence between nuclear loci and COII. 
La Réunion Cratopopsis group

-Cratopus ditissimus (La Réunion)

0.551 Cratopus nanus (La Réunion)

4 Cratopus humeralis group (La Réunion)

Cratopus inornatus (Rodrigues)

0.54-Cratopus subdenudatus (Grande Comore)

$0.59 \quad$ Cratopus LaDigue sp1 (La Digue)

0.99 Cratopus aurostriatus (La Digue)

Scaevinus subtruncatus (Mauritius)

$0.61 \quad 0.95 \quad$ Cratopus bernei (La Réunion)

1 Cratopopsis pauliani (Rodrigues)

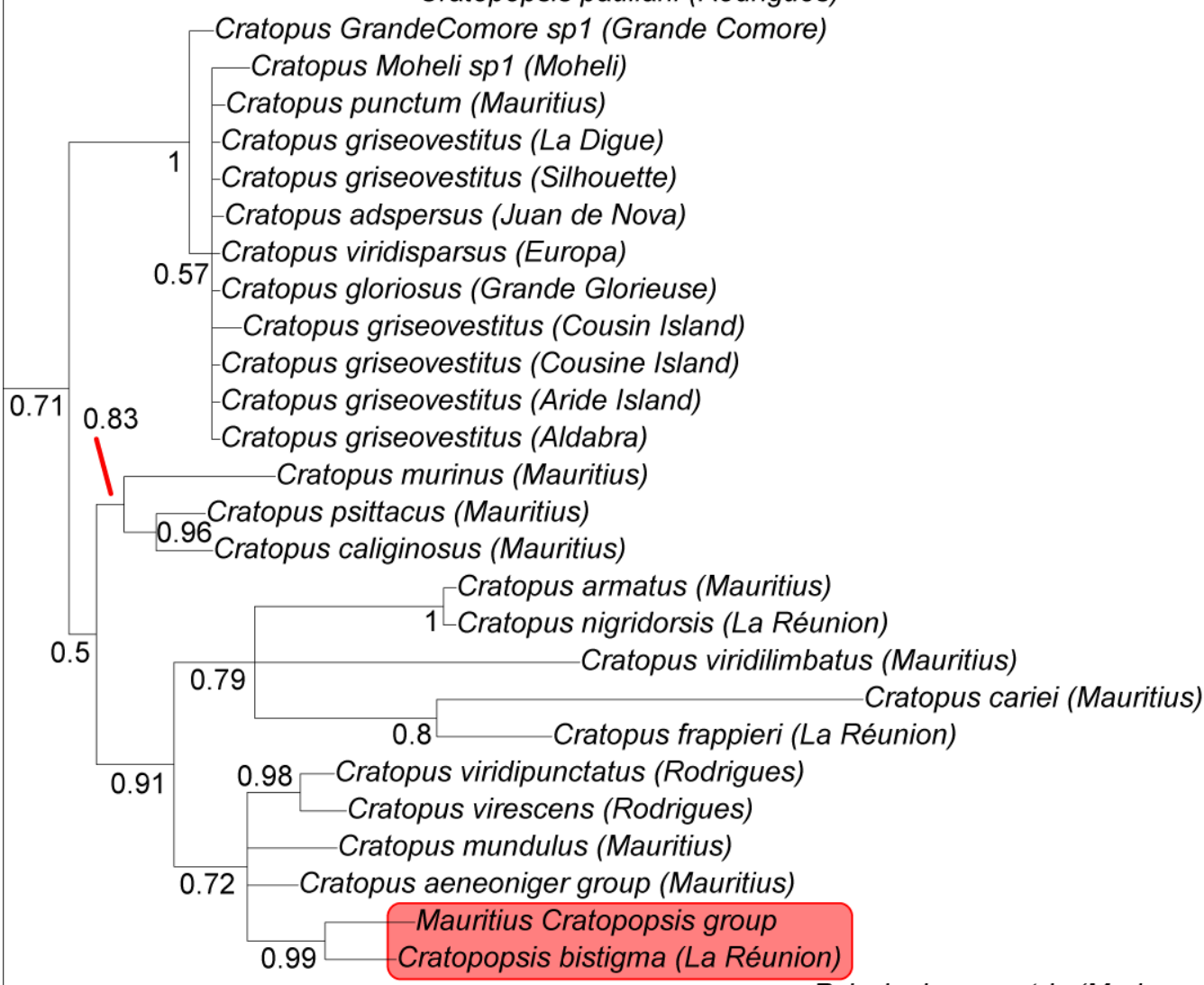

$-0.01$

Fig S2.5: A Bayesian inference tree generated by MrBayes using an alignment of Cratopine Histone 3 sequences. Values placed on nodes represent Bayesian posterior probabilities for that node. Cratopopsis bistigma and Cratopopsis mauritianus are highlighted to show incongruence between nuclear loci and COII. 
Cratopus LaDigue sp1 (La Digue) Cratopus segregatus (Praslin)

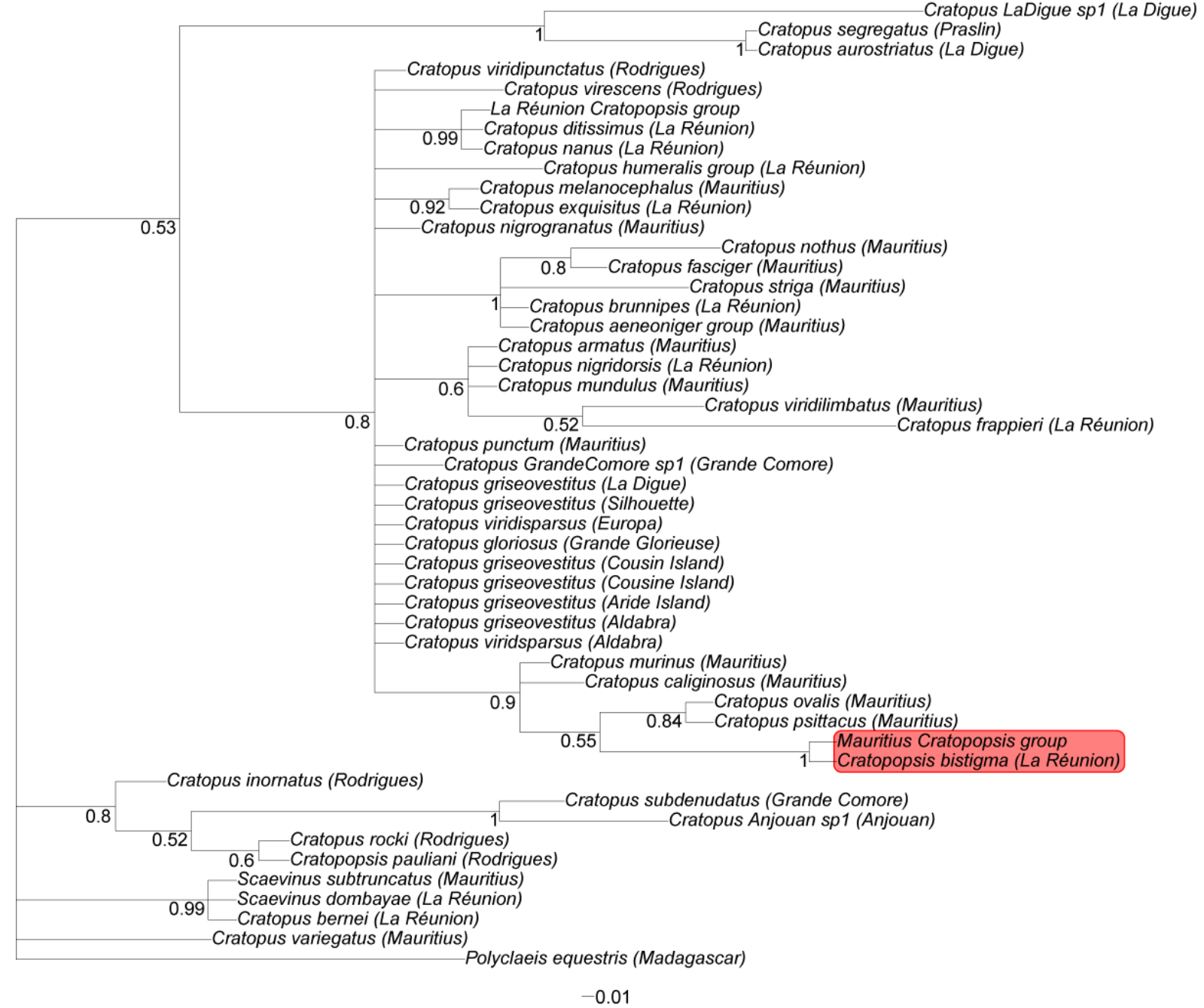

$-0.01$

Fig S2.6: A Bayesian inference tree generated by Mr Bayes using an alignment of Cratopine 28S sequences. Values placed on nodes represent Bayesian posterior probabilities for that node. Cratopopsis bistigma and Cratopopsis mauritianus are highlighted to show incongruence between nuclear loci and COII. 
-Polyclaeis equestris (Madagascar)

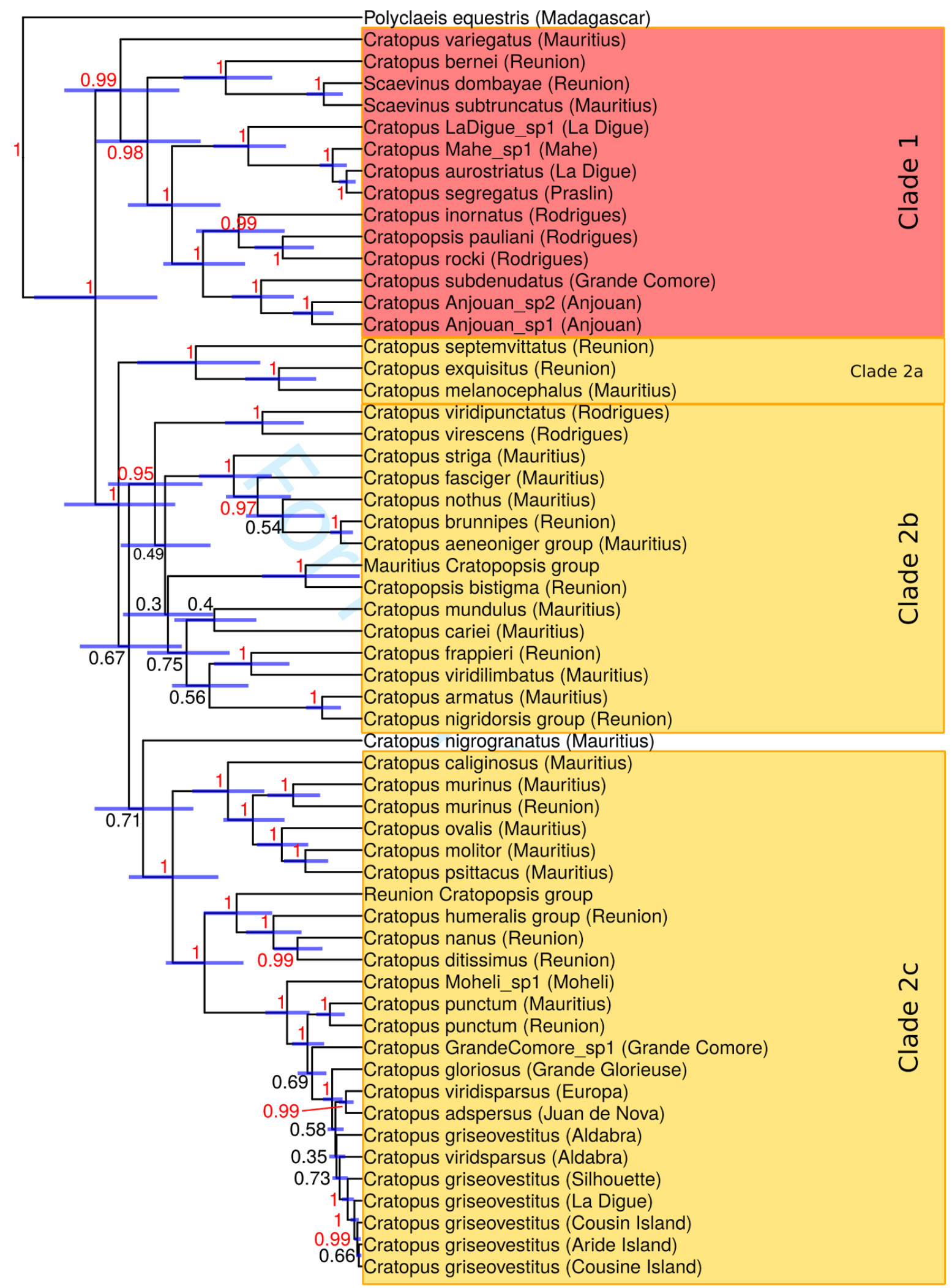

Fig S2.7: A Bayesian inference chronogram generated by BEAST2 using all four loci. Values placed on nodes represent Bayesian posterior probabilities for that node, blue bars on nodes represent the $95 \%$ HPD interval on node heights. 


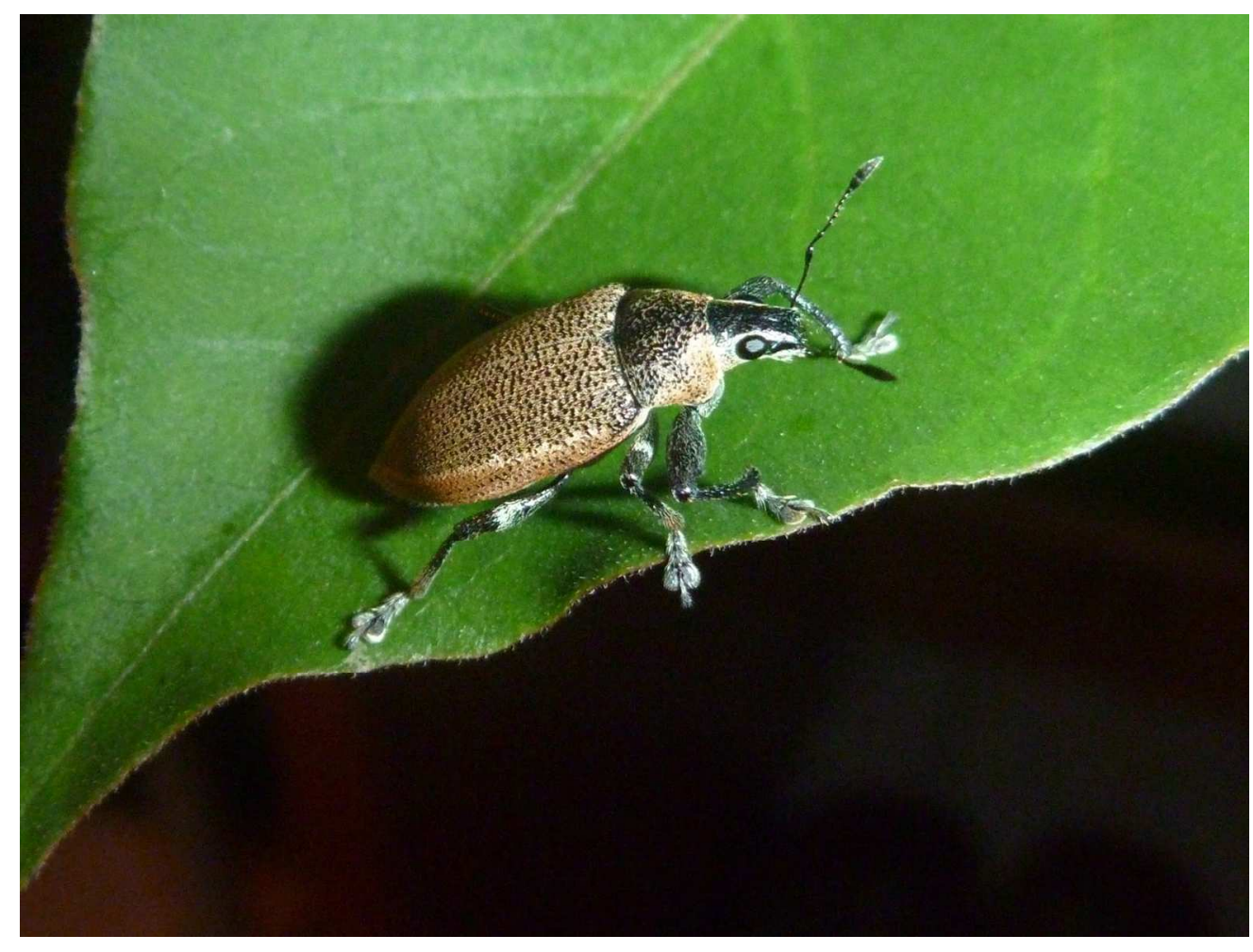

Twitter image $288 \times 216 \mathrm{~mm}(180 \times 180$ DPI $)$ 
Cirque de Mafate on Reunion Island as seen from Col de Boeufs inset with examples of the species rich Cratopine weevils found throughout the Mascarene islands. From left to right: Cratopus marmoreus (Reunion), Scaevinus dombayae (Reunion), Cratopus fasciger (Mauritius) 